CuPAUAM 25.1, 1998, pp. 87-118

\title{
CAMBIOS EN EL EQUTPAMIENTO INSTRUMENTAL ENTRE EL PALEOLITICO FINAL Y EL EPIPALEOLÍTICO: LA CUEVA DE LA PILA
}

CARMEN GUTIÉRREZ

Universidad Autónoma de Madrid

\begin{abstract}
Resumen (Cantabria).

Análisis de la evaluación tecnologica y formal del instrumental lítico y óseo en la Cueva de la Pila
\end{abstract}

Summary

Anaiysis of the technological and formal evolution of lithic and bone instruments at 'Cueva de la Pila' (Cancabria).

Se sitúa en el pueblo de Cuchía (Miengo, Cantabria) muy próxima a la playa de Marzán a y la ría San Martín de la Arena, donde desemboca el Saja-Besaya. Localizada en el límite de las explotaciones de caliza de Solvay-Mitosa S.A., durante la Prehistoria su entorno debió de ser muy distinto, ubicándose en la base de una suave colina hoy desaparecida por la cantera.

El poblamiento de la zona es muy antiguo, las numerosas piezas encontradas en los alrededores de la cueva remiten al Paleolítico inferior. Los restos de esta época, bifaces y hendedores, sobre todo, han aparecido en superficie, en la zona entre la cueva y el pueblo de Cuchía.

Sin embargo la ocupación principal de la cueva de la Pila es mucho más reciente, no más allá de unos 13.000 años y se prolonga de manera imprecisa hasta casi la Edad Media. El yacimiento formado por estas ocupaciones se sitúa en dos zonas: el pasillo de 
entrada, con unos $10 \mathrm{~m}$ de largo y casi $4 \mathrm{~m}$ de anchura, que conforma un área alargada de unos $40 \mathrm{~m}^{2}$, y un pequeño vestibulo de acceso a una sala circular situado a unos $25-30 \mathrm{~m}$ de la entrada de la cueva.

Los niveles del yacimiento en la zona de la entrada de la cueva, permiten distinguir tres grandes momentos:

Fase I. Las ocupaciones más antiguas sucedieron aproximadamente entre $13.000 \mathrm{y}$ 12.000 años antes del presente, correspondiendo al complejo Magdaleniense. Se encuentran en los niveles arqueológicos IV-4 a IV-1, separadas del conjunto superior por un nivel arcilloso casi estéril (III-4b).

Fase II. A continuación la cueva fue habitada durante el Aziliense (niveles III- 4 a III1) que se datarian "grosso modo" entre 12.000 y $11.000-10.500$ años antes del presente.

Fase III. Los dos estratos superiores (I y II) han dejado escasas evidencias de ocupación, pero diversas en su cronología. Estos niveles estaban muy revueltos y contenían restos mezclados que pueden encuadrarse en el Calcolítico-Bronce pleno, Edad del Hierro, épocas romana y medieval, además de materiales actuales (vidrio, latas...)

Las fases I y II se encontraron solamente en el pasillo de entrada de la cueva; la fase III apareció también allí y en el vestibulo intexior. En esta última zona aparecía un gran socavón realizado por las gentes del pueblo para extraer "tierra negra muy buena como abono para los prados ${ }^{n 113}$. A lo largo de este siglo se han ido sacando estas tierras negras de la cueva de la Pila y para ello entraban con carros a cargarlas, destruyéndose así los niveles superiores del pasillo (I y II) y todo el yacimiento interior: Ias evidencias que quedan de ésta última zona apuntan al uso de la cueva como lugar de enterramiento: un fragmento de calota craneal en superficie en el pasillo de entrada, algunos fragmentos cerámicos y una punta de flecha como parte probable de un ajuar, que remitirian a una cronología lata entre Calcolítico y Bronce, momento en que son comunes los enterramientos colectivos en cueva en algunas zonas de la Cornisa Cantábrica. ${ }^{[2]}$. Por su parte la información de la gente del pueblo alude a huesos humanos en las tierras negras además de la propia evidencia de estas tierras que por su color indican desechos de materia orgánica dentro de un sedimento arcilloso propio de la cueva. Lamentablemente cuando la cueva fue excavada todo el área de tierras negras del interior había sido saqueada, quedando únicamente una gran fosa estéril, constituido por arcillas limpias con algunas manchas grisáceas en su perfil.

Por otra parte delante mismo de la boca de la cueva, la empresa Solvay-Mitosa S.A. había extraido gran cantidad de tierra durante unas obras de prospección del terreno. En los perfiles de este nuevo socavón y junto a la boca exterior quedaban algunas evidencias de ocupaciones indeterminadas constituidas por restos de moluscos, fauna y lascas, todo ello en muy pequeño número.

[1] Segün nos comunicaron dirante las campañas de la excavación algunas gentes del pueblo. Incluso en la huerta de uno de los vecinos se enconiró un hacina pulimentada, que bien pudiera haber sido arojada alï junto con ia tierra empleada como abono.

[2] Armendariz 1990 . 
Todo apunta a una intensa ocupación humana de la cueva y su entorno a lo largo de distintas épocas desde la Prehistoria mas antigua, no obstante las diversas actuaciones humanas durante este siglo solo han permitido documentar adecuadamente una parte de esta secuencia que se encuadra en el tránsito del Paleolítico reciente al Epipaleolítico y se situaba junto a la boca de la cueva a lo largo del pasillo de acceso hacia el interior.

\section{IAS OCUPACIONES MAGDALENIENSES}

\section{Estratigrafia, cronologia y entorno medioambiental}

Se inician en la base de la estratigrafía sobre un nivel de arcillas estériles con algunos bloques caídos del techo, de su superficie se extrajeron escasos restos arqueológicos que probablemente pertenezcan al nivel IV-4, primera ocupación de la cueva. Estratigráficamente las ocupaciones magdalenienses son las siguientes:

IV 1 tierra negra muy grasienta, con algunos cantos y escasos restos de moluscos. Magdaleniense final

IV.2. marrón arcilloso, de débil desarrollo junto a la boca de la cueva y muy espeso en el interior. Magdaleniense final. $12.200+70 \mathrm{BP}$

IV.2b. capa de arcillas finas muy limpias y escasa potencia. Estéril

IV.3. negro, como IV.1 y IV.4 de tierra grasienta. Magdaleniense superior

IV.3b. lentejones de arcillas finas muy limpias que separaban IV.3 y IV.4 en algunas áreas

IV.4. muy negro. Magdaleniense superior

$\mathrm{V}$ arcillas de base

Los primeros habitantes de la cueva de la Pila se instalaron a lo largo del pasillo de entrada y la sedimentación de sus residuos forma el nivel IV.4 -de unos $8-10 \mathrm{~cm}$ por término medio-. Después de esta primera estancia se evidencia un momento de desocupación, representados por las arcillas del nivel IV.3b; este sedimento es muy delgado -igual o menor de $2 \mathrm{~cm}-\mathrm{y}$ aparece muy limpio; por otra parte no se extiende por todo el área de habitación. La siguiente ocupación se refleja en los restos del nivel IV.3, similar al anterior. Como él va seguido de un espacio indeterminado de tiempo en el que la cueva per* manece deshabitada -nivel IV.2b-.

El tercer grupo de ocupaciones tiene características diferentes. Se trata de un nivel de arrastre, muy fino en la entrada de la cueva que se va engrosando según avanza al interior. En él las piezas aparecen frecuentemente en posición vertical o inclinada. Este hecho indica que una vez abandonada la cueva, durante la sedimentación de los restos, hubo una entrada de agua y quizá barro que fue arrastrando al nivel arqueológico hacia el interior, causando la alteración del material arqueológico. Es el nivel más rico en restos y de mayor potencia estratigráfica -hasta $40 \mathrm{~cm}$ en el fondo de la cueva-, pero dado su carácter revuelto es prácticamente imposible saber si engloba una o más ocupaciones. 
Finalmente se da la última presencia magdaleniense en el nivel IV $1-5$ a $8 \mathrm{~cm}-$, que, a diferencia del anterior, presenta mayor homogeneidad a lo largo del área ocupada. En sus zonas superiores aparecieron restos de moluscos, Patella y Littorina littorea, pero no parece que se trate de productos consumidos por este grupo magdaleniense sino que pueden pertenecer al nivel inmediatamente superior -Aziliense- hundiéndose en el estrato magdaleniense debido a la presión del sedimento.

Los niveles negros aparecen relativamente intactos, su color indica que hubo abundante materia orgánica en descomposición ${ }^{[3]}$, sin embargo es imposible determinar si corresponden a alojamientos únicos de carácter prolongado o a varios continuados, ya que en todos los niveles la presencia de restos es muy homogénea y no se pudo identificar unidades indiviđuales más pequeñas. Los únicos momentos de desocupación, bien documentados, corresponden a los niveles IV2b y IV3b que se han formado debido a la decantación de arcillas entradas desde la boca y el techo de la cueva. No hay que olvidar que esta se situaba en la base de una suave colina, lo que facilitaba la entrada de agua y sedimentos en momentos húmedos. Los análisis de las piezas dentales de los molares de cérvidos -en curso de estudio- podrán informar con mayor fidelidad sobre las épocas de ocupación de la cueva y, en consecuencia si se trata de hábitats temporales de tipo estacional o bien de ocupaciones más breves y puntuales con un objetivo más específico.

El único nivel magdaleniense datado por C14 es el IV.2, que ha dado una fecha de $12.200 \div 70 \mathrm{BP}$ (Gif 8149)(4). Por el carácter y homogeneidad de la industria me inclino a pensar que la presencia magdaleniense en la cueva de la Pila se puede encuadrar entre 13.500/13.000 BP hasta aproxinadamente 12.000 BP., un lapso de tiempo muy corto -unos 1500 años según una estimación grosera- para una potencia estratigráfica amplia. Esta datación situaría la ocupación magdaleniense más potente de la Pila en el nivel IV.2- en la fase Cantábrico VII del Würm IV(5), -11.700 a $12.700 \mathrm{BP}$, asimilable relativamente al Dryas II de la secuencia polínica; el clima es frio y ligeramente húmedo al inicio de la fase y se va tornando más seco y árido según avanza esta.

Otras referencias climáticas aportan los análisis antracológicos ${ }^{[6]}$. El conjunto magdaleniense evidencia condiciones frías pero no rigurosas, quizá matizadas por la proximidad del mar y una buena exposición. La vegetación incluye coníferas, enebro y pino, además abedul, presencia esporádica de castaño y leguminosas. El descenso de enebro desde la base de la secuencia hasta las ultima ocupaciones magdalenienses ha sido interpretado como una tendencia progresiva al mejoramiento climático. Es decir, en el entorno de la Pila, durante el Magdaleniense no faltaron bosques de pino y enebro, situándose probablemente ya que las coniferas debieron de situarse en zonas altas más alejadas; en áreas más abrigadas pequeñas manchas de castaños y en zonas abiertas leguminosas.

(3) Este hecho era patente incluso durante su excavación dado el mal olor que desprendian.

[4] De todas las muestras tomadas a lo largo de la secuencia solo las procedentes de este nivel y otro azilense han dado resultados, el resto no contenía suficiente materia orgánica.

[5] Seguñ propuesta paleoclínácica del Tardiglaciar cantăbrico de Hoyos, M. (1995: 55 y ss).

66] Bermaldo de Quiros et alì 1988. 
Entre la fauna de estos niveles, actualmente en estudio, un alto número de restos óseos parecen pertenecer a ciervo, mientras que el caballo, aunque documentado, era mucho menos abundante. Este dato permite deducir igualmente la pervivencia de masa boscosa en el área de captación de la Pila en detrimento de espacios abiertos, lo que quizá pudiera deberse a las favorables condiciones de situación a pesar de encuadrarse en un ambiente general tan frío como el Dryas II.

A pesar de su ubicación junto al mar los grupos magdalenienses explotaron poco la zona costera ya que no se documentan restos de moluscos, y en consecuencia marisqueo, en sus estratos siendo, por otra parte, extremadamente abundantes en los niveles azilienses. Otro problema presenta la pesca o más propiamente la caza de peces ya que sólo se ha recogido alguna vértebra de pez, quizá salmónido por el tamaño; sin embargo, la fragilidad de estos restos óseos o bien el tipo de preparación o el lugar donde se realice pudieran enmascarar este aparente desinterés por los recursos costeros y fluviales. Por otra parte la situación de la cueva es inmejorable para la captura de peces dada la proximidad de la ría y de la costa, además estos niveles han proporcionado un alto número de arpones magdalenienses, varios de ellos rotos por el uso, lo que confirma estas capturas.

\section{La industria litical ${ }^{[7]}$}

Aunque no está completo su estudio hay ya una serie de datos que permiten un avance en cuanto a su evolución, por lo que las conclusiones de este trabajo respecto a la lítica atenderán únicamente al utillaje retocadolsl y al esbozo de cadena operativa del nivel IV-41010].

El número total cie instrumentos retocados ofrece una distribución desigual a lo largo de los niveles magdalenienses dándose los mínimos al inicio de la secuencia durante el Magdaleniense superior y creciendo sobremanera en el Magdaleniense final, especialmente en el nivel IV-2 cuyos 930 útiles superan con creces al resto de la secuencia; en esta misma etapa, además, no solo hay mayor número de instrumentos sino también la variedad tipológica es mucho más alta que en la fase previa. Estos datos concuerdan con la distribución de las piezas oseas que tienen su máxima presencia durante esta fase, justamente en el nivel IV-2.

Es preciso señalar que el elemento común a toda la secuencia es la altísima presencia de pequeñas Iaminillas, que llegan a suponer en torno al $50 \%$ de cada conjunto, hecho que minimiza porcentualmente la valoración de los cambios en el resto del instrumental.

Utillaje microlaminar. Su importancia es innegable tanto en las ocupaciones magdalenienses como en las azilienses. El enorme desarrollo de este grupo se debe principal-

[7] Ver apéndice 1.

[8] Láminas IV y V.

[9] El estudio del utillaje retocado se ha tomado de Lagüera Gaxcía 1991, a el se deben las cifras absolutas y la interpretación de esta industria.

[10) Lloret 1997 
mente a la altísima presencia de las hojitas de dorso en toda la secuencia cuyo índice restringido está siempre por encima del $70 \%$. Se trata en su mayoría de piezas que presentan retoque abrupto en un solo lateral, siendo muy escasa la incidencia de las de doble dorso en todos los niveles magdalenienses, por otra parte la presencia de hojitas apuntadas oscila entre $5.54 \%$ en el nivel IV-1 y el $10.37 \%$ del IV-3 (Lagüera García 1991). No obstante hay otros tipos de hojitas cuya distribución varia por fases, así por ejemplo el peso de las hojitas denticuladas, especialmente de dorso denticulados, es mas fuerte durante el Magdaleniense superior, descendiendo su importancia en los momentos posteriores. En una tendencia contraria evolucionan otros tipos como las hojitas truncadas y las puntas azilienses que crecen porcentualmente de base a techo de la secuencia.

Raspadores. Como conjunto ofrecen un desarrollo progresivo desde los niveles de base donde apenas alcanzan el $5.7 \%$ y el $8.5 \%$ hasta el Magdaleniense final, en cuyo nivel IV-1son el segundo grupo en importancia. Los tipos principales son los simples, mayoritarios en todos los niveles excepto en el IV-4 y los realizados sobre lasca, un poco más abundantes en este último nivel. Los raspadores sobre lámina retocada aparecen medianamente representados entre los niveles IV-3 y IV-1 mientras que los tipos elevados, tan característicos del Magdaleniense inferior tienen una presencia bastante exigua y muy limitada al nivel IV-2. Los raspadores carenados y unguiformes, tan propios de los complejos industriales azilienses, no se documentan durante el Magdaleniense superior y empiezan a estar presentes en el final aunque en escaso número.

Buriles. Inversamente a los raspadores ven disminuir su presencia desde el Magdaleniense superior, en cuyo nivel de base alcanzan el $10.4 \%$, hasta el final donde apenas suponen el 4.6\%. En todos los niveles aparecen diversificados en distintos tipos siendo un poco más importantes los diedros, en especial aquellos realizados a partir de un plano natural de rotura. Es de destacar también la variedad de buriles sobre truncadura en el nivel IV-2, donde están representados casi todos los tipos sí bien en muy pequeña cantidad.

Piezas con dorso y truncadas. En este grupo está constituido por un conjunto diverso de instrumentos que se dividen en puntas y piezas con retoque abrupto en uno o dos de sus extremos o bien sobre sus laterales y crecen progresivamente a lo largo de la estratigrafia. De todas ellas son las truncaduras las mejor representadas, tanto en frecuencias como en variedad de tipos; destacan las truncaduras convexas en el nivel IV-1 y las cóncavas en los siguientes. Con menor importancia cuantitativa las piezas con muesca se constatan durante el Magdaleniense superior y se agotan en los momentos finales de la fase siguiente donde ya no aparecen. Los bordes abatidos apenas están representados y las puntas, de diversa morfología, ofrecen un incremento paulatino desde el nivel IV-3 de las llamadas azilienses a las que se unen además unas pocas microgravettes durante el Magdaleniese final.

Piezas de retoque continuo. A la inversa que con el grupo anterior las piezas de este conjunto van decreciendo desde las primeras ocupaciones hasta el Magdaleniense final. En el nivel de base destacan sobre todo las piezas que poseen un solo borde retocado mientras que en los niveles siguientes se van igualando con las de retoque continuo sobre dos bordes. Dentro de este grupo sobresalen cualitativa que no cuantitativamente las denominadas láminas magdalenienses, que alcanzan cierta importancia en el Magdaleniense supe- 


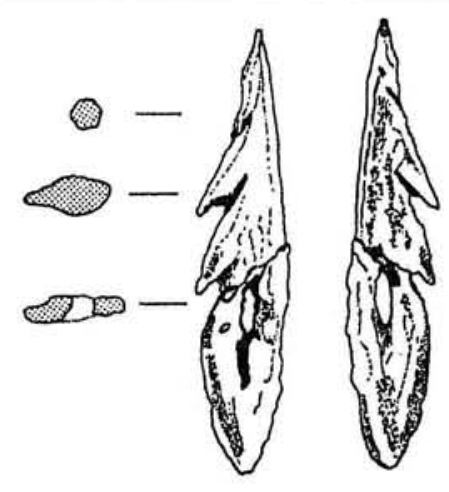

1. Nivel III-1

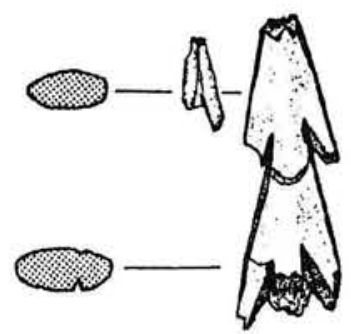

3. Nivel III-3

Dibujos A. Bueno
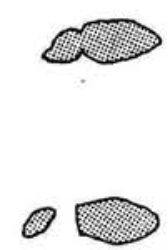

$\rightarrow 0$

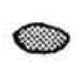

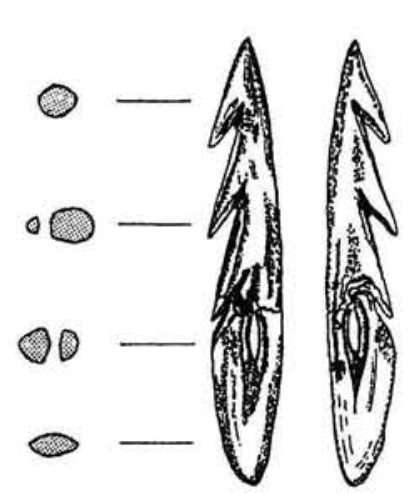

2. Nivel III-3
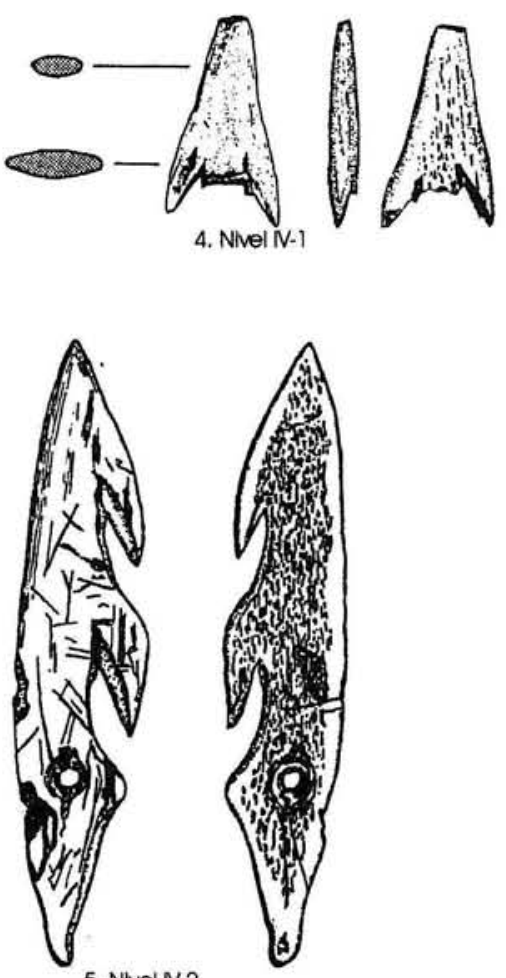

Lámina I. 

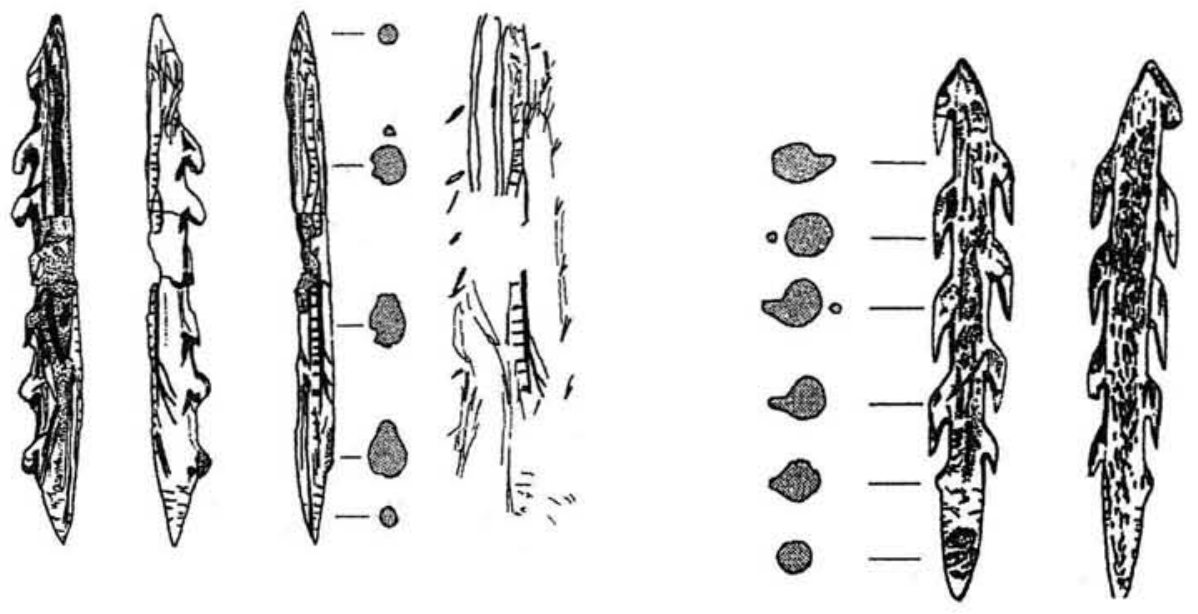

1. N|vel |II-4b

2. Nivel IV-2
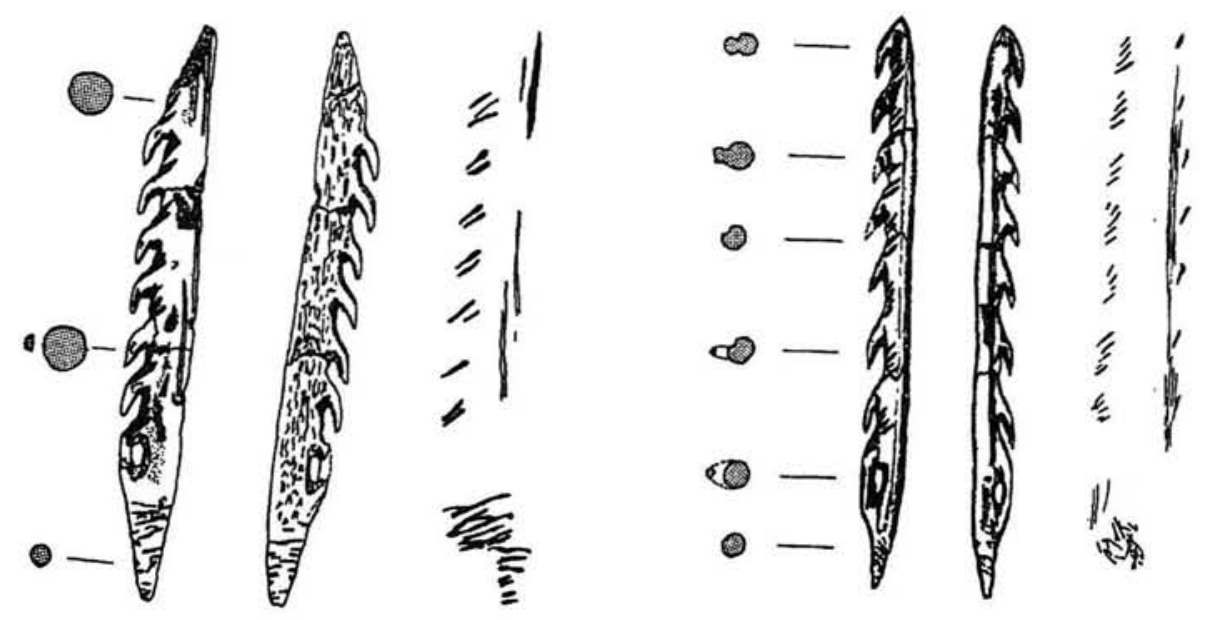

3. Nivel IV-2

4. Nivel IV-4

Dibujos A.Bueno

Lámina II 
rior francés; son hojas apuntadas recubiertas con retoque escamoso, en la Pila aparecen durante el Magdaleniense final con un poco mas de peso y durante el superior se atestiguian en el nivel IV-4, siendo sustituidas en el IV-3 por hojas apuntadas pero modificadas por retoque simple. También en este grupo he incluido una pieza ajena a él y propia de contextos culturales muy anteriores, concretamente solutrenses. Se trata de una punta de cara plana, tallada sobre un sílex de buena calidad y convertida en buril diedro sobre roturá; ambas partes de la punta se encontraron en distintos sectores del mismo nivel (Lám. V:A). La materia sobre la que se talló esta bella pieza es la misma ${ }^{[11]}$ que emplearon los magdalenienses de la Pila para hacer algunos de los mejores útiles pero apenas hay núcleos o desechos de talla de ella por lo que parece tratarse de una materia apreciada aunque probablemente de una zona alejada. La punta no es originaria del yacimiento porque en la base de la secuencia de la cueva de la Pila solo se documentan ocupaciones anteriores al Magdaleniense superior, por lo que parece haber sido traída de fuera, quizá de la zona de abastecimiento de este silex de calidad.

Sustrato. Presenta unas proporciones moderadamente bajas y desigual composición en las dos fases. Aunque las piezas astilladas predominan en los cuatro niveles, con una frecuencia en torno al 5\%, durante el Magdaleniense superior también poseen cierta entidad las piezas con escotadura e incluso los denticulados, en la fase siguiente este grupo aparece dominado en exclusiva por las piezas astilladas.

Perforadores y Utiles compuestos. Ambos conjuntos son poco significativos en la secuencia de la Pila. En los niveles de base están representados por una pieza de cada en el nivel IV- 4 y ausentes en el inmediatamente superior IV-3; en el Magdaleniense final aunque ofrecen mayor diversidad de instrumentos su índice no sobrepasa el 1.5\%, destacando los compuestos, y entre ellos los raspadores-buril, en el nivel IV-2 y los perforadores en el IV-1.

Esta es la composición tipológica del instrumental Magdaleniense de la Pila. A falta de un estudio más amplio, en preparación, se ha publicado un avance de la cadena operativa del nivel IV-4. A partir de la distinción de las materias primas, el estudio de núcleos y otros productos así como de los remontados que se han podido llevar a cabo he aquí las conclusiones de este avance preliminar ${ }^{[12]}$.

Respecto a las materias primas predominan los sílex de los que se detectan hasta cuatro tipos, algunos de ellos con una gran diversidad interna en cuanto a su tonalidad, de los cuatro hay uno excelente, dos mediocres y un último de mala calidad para la talla. Las cuarcitas se unen en un único grupo, también variable en colores y con calidad intermedia. Hay además otras rocas en menor proporción, entre ellas dos tipos de arenisca de grano fino y medio y cristal de roca. El predominio del sílex en todo el conjunto y muy especialmente en los útiles retocados no deja de extrañar ya que la Pila se ubica en la zona central de Cantabria, fuera del área de buenos recursos litológicos que comprende la zona oriental y

[11] Lagüera Gaxcía 1991. 83.

(12) A partir de datos tomados de Lloret 1997. 
el País Vasco. No obstante habría que matizar la calidad de este silex no solo en cuanto a sus cualidades para la talla sino también mediante las longitudes de los soportes obtenidos y su relación con el indice de laminaridad o el grado de aprovechamiento.

De las 1951 piezas incluidas en esta unidad los soportes sobre lasca suponen el grueso del conjunto $-68.4 \%$ - frente a los laminares $-22 \%$ - y otros $-9.6 \%$ - Los distintos pasos de las cadenas operativas se distribuyen de la siguiente manera:

\begin{tabular}{|c|c|c|c|c|c|}
\hline Fases de la cadena operativa & Blementos de la cadena operaciva & Silex & Silex & \multicolumn{2}{|c|}{ Cuarctia } \\
\hline $\begin{array}{l}\text { Desbascado, calla del núcleo } \\
\text { y desechos }\end{array}$ & $\begin{array}{l}\text { Piezas con córtex } \\
\text { Elementos de preparación del rúcledił } \\
\text { Núcleos y restos de núcleo } \\
\text { Chunks y fragmentos indetermirados } \\
\text { Golpes de buril }\end{array}$ & $\begin{array}{rr}417 & 26.7 \\
113 & 7.2 \\
29 & 1.8 \\
53 & 3.4 \\
19 & 1.2\end{array}$ & & $\begin{array}{r}220 \\
2 \\
2 \\
- \\
-\end{array}$ & $\begin{array}{r}55.8 \\
0.5 \\
0.5\end{array}$ \\
\hline Soportes & $\begin{array}{l}\text { Iascass no corticales } \\
\text { Láminas } \\
\text { Laminillas }\end{array}$ & $\begin{array}{rr}577 & 37.0 \\
233 & 14.9 \\
116 & 7.4\end{array}$ & & $\begin{array}{r}163 \\
6 \\
1\end{array}$ & $\begin{array}{r}41.3 \\
1.5 \\
0.2\end{array}$ \\
\hline & TOTAL & 1557100.0 & & 394 & 100.0 \\
\hline Piezas retocadas & $\begin{array}{l}\text { Ufiles sobre lasca } \\
\text { Útiles sobre lámina } \\
\text { Utilles sobre lanuniflas } \\
\text { Oros }\end{array}$ & $\begin{array}{r}27.0 \\
22.9 \\
47.0 \\
2.9\end{array}$ & $\begin{array}{l}44,5 \\
72.5 \\
84.0\end{array}$ & & \\
\hline
\end{tabular}

Dentro de este conjunto el silex representa prácticamente el $80 \%$ entre las materias empleadas en la ocupación basal de la Pila. La cadena operativa de la cuarcita es, cuando menos, extraña; va dirigida a la obtención de lascas dado que las laminas y laminillas obtenidas de ella son anecdóticas, sin embargo lo desconcertante es que la alta presencia de piezas corticales en el nivel parece aludir a labores de talla en el yacimiento pero los escasísimos núcleos y elementos de preparación no corroboran esta hipótesis; habría que pensar que la talla se produjo fuera de la cueva y se introdujeron en ella los diversos soportes con o sin cortex. Con el sílex se observa una situación muy parecida en cuanto al desequilibrio entre soportes y productos del proceso de lascado, si bien el funcionamiento de esta materia es más complejo. Aquí están bien representadas las fases del proceso de talla laminar aunque en baja proporción.

Los soportes, a su vez, son variados siendo las lascas mayoritarias y doblando las laminas a las laminillas. En proporción inversa los instrumentos retocados son en su mayoría hojitas y en segundo término lascas y láminas, ambas aparecen casi igualadas, si bien son un poco más numerosos los útiles sobre lasca. En idéntico orden el empleo de sílex de la mejor calidad se ha dedicado a hojitas, láminas y lascas respectivamente, estando igualada en estas ultimas la proporción de silex bueno y mediocre.

Las cadenas operativas son para Lloret ${ }^{[14]}$ las siguientes: en silex se detectan una de soportes laminares de tamaño medio que a partir de la reducción del núcleo en el proce-

[13] Láminas y subláminas de cresta, tabletas y semitabletas, etc.

[14] 1997: 145. 


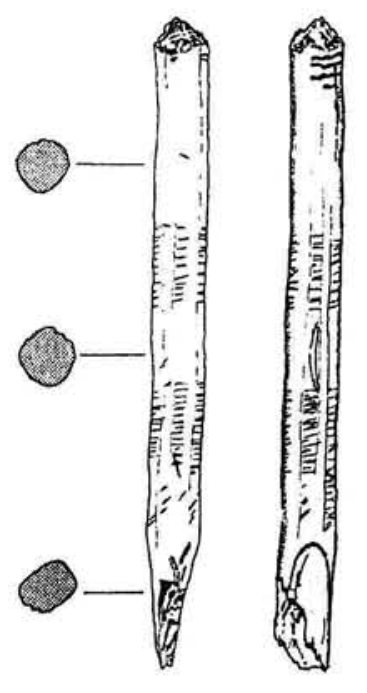

1. Nivel IV-2

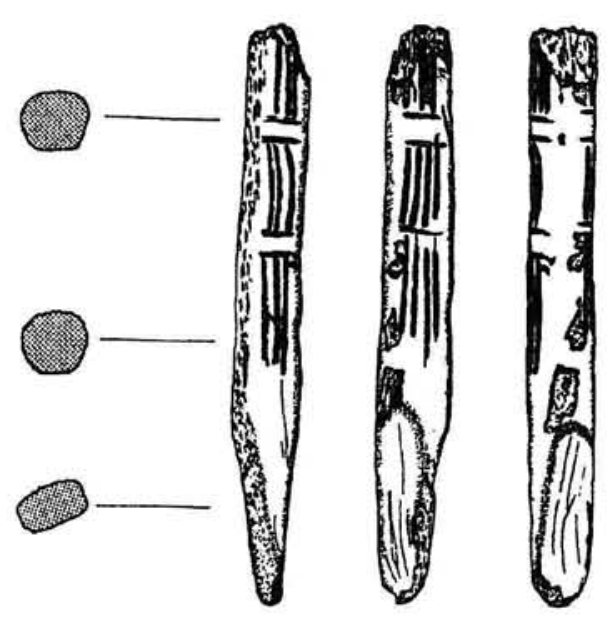

2. Nivel IV-2
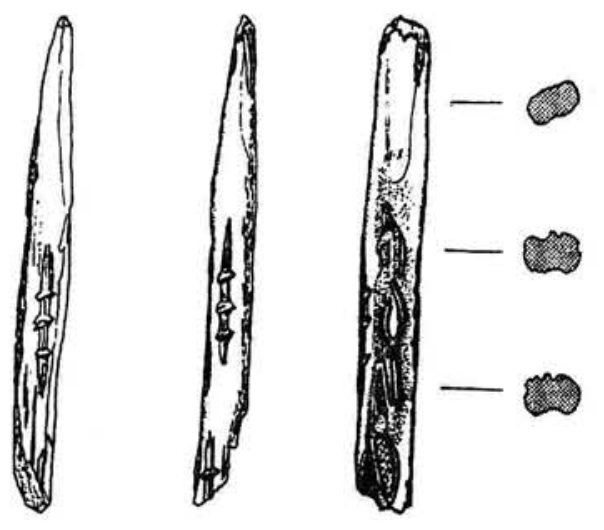

4. Nivel IN-2

3. Nivel IV-4

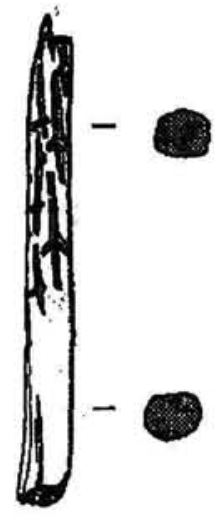

Dibujos A. Bueno

Lámina III 


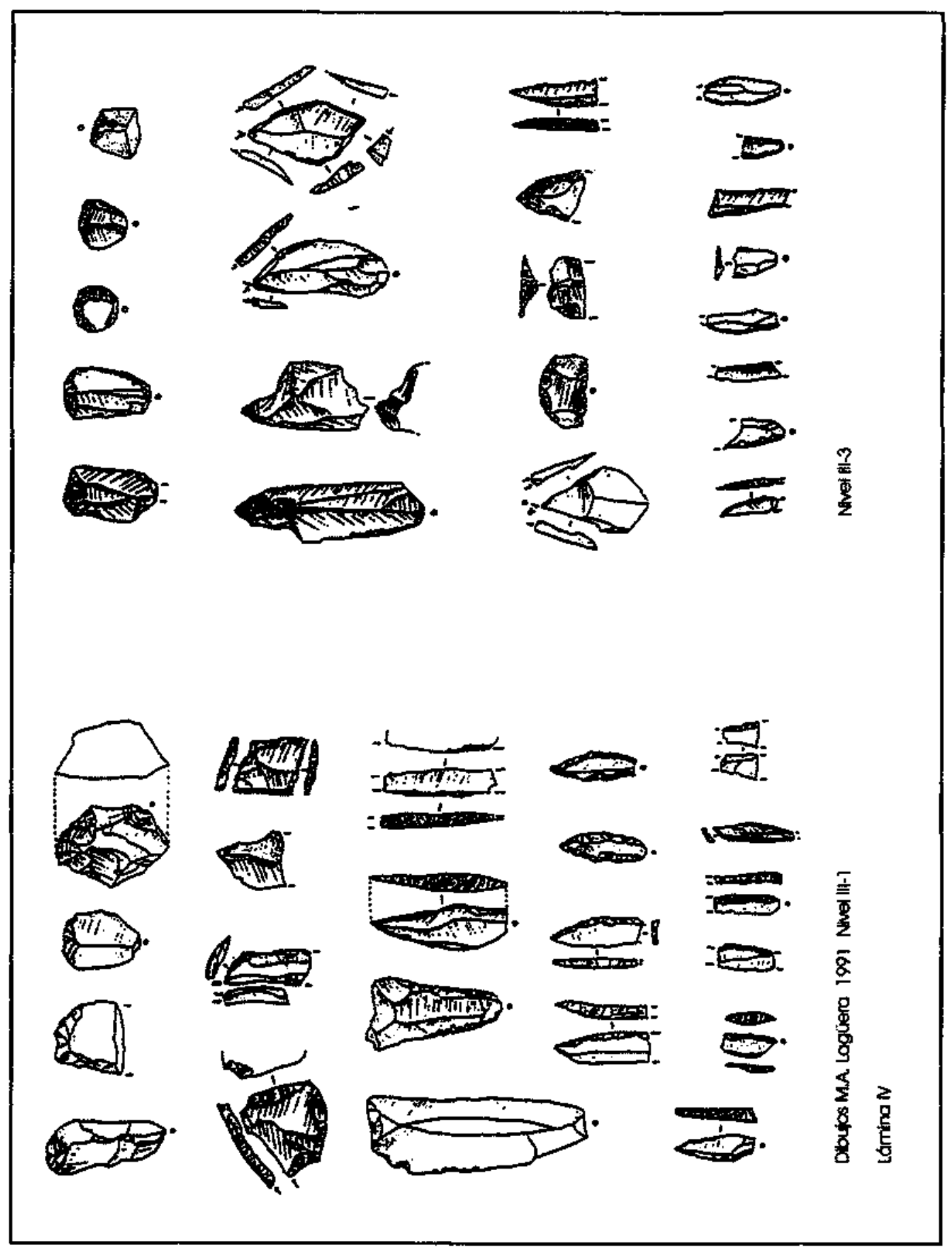

Lamina $I V$ 
so de lascado se reconvierte en cadena de hojitas ${ }^{[15]}$ y otra destinada a la producción de lascas de mediano-pequeño tamaño. En cuarcita la cadena principal se destina a obtener lascas, aunque la presencia de láminas, una hojita de dorso y una lámina de cresta en este material indica al menos una producción secundaria de elementos laminares.

Ütiles. De los soportes en laminilla un $85 \%$ se ha transformado en hojitas de dorso. De ellas la práctica mayoría se ha ejecutado sobre el sílex de mejor calidad. Es significativa la preferencia de soportes en atención a los diversos instrumentos, aunque entre los útiles menos abundantes algunos de ellos como piezas truncadas, con dorso o con muesca se ejecutan indistintamente sobre hoja o lasca. Las lascas se dedican a obtener buriles y en menor cantidad raspadores o simples lascas retocadas; las láminas, a su vez, se retocan sobre uno o dos bordes, se les aplica la técnica del golpe de buril o incluso se transforman en hojitas de dorso, quizá en un intento de aprovechamiento máximo del sílex de buena calidad, el mismo que mayoritariamente presentan estas piezas ejecutadas sobre soporte de hojitas. Este grado de máximo aprovechamiento del sílex bueno se desprende también del estudio de los núcleos de laminillas; en ellos el agotamiento es total pero una vez que ya no pueden seguir sacando pequeñas hojitas en dos casos al menos se han reconvertido en raspadores nucleiformes.

Como conclusión provisional se puede adelantar el interés de los ocupantes de la base magdaleniense en la Pila por la búsqueda y agotamiento de un silex de buena calidad que junto con otros más mediocres se destina básicamente a la producción de hojitas de dorso, soportes laminares medianos encaminados a la fabricación de buriles, hojas retocadas e incluso más hojitas de dorso y, en menor medida, lascas de las que se obtienen buriles, raspadores y piezas de retoques diversos. De manera alternativa utilizan materias más bastas como cuarcita y puntualmente arenisca y cuarzo.

\section{Las industrias óseas ${ }^{[16}$}

Son muy ricas en el magdaleniense de la Pila pero se dan con distinta intensidad a lo largo de la secuencia. Destacan las 75 piezas del nivel IV-2 que triplican en número al resto de los niveles ( 22 en IV-4, 26 en IV-3, 26 en IV-1), muy igualados entre sí.

Entre los diversos elementos sobresalen en ambos conjuntos las azagayas (29 en el Magdaleniense superior y 21 en el final) seguidas de arpones ( 4 y 11), punzones ( 3 y 11), agujas y núcleos (5 y 6 más 3 núcleos del Magdaleniense superior) y los 12 dientes perforados del Magdaleniense final frente a solo 3 en el superior. El resto del conjunto, aunque variado, aparece en muy pequeña cantidad.

Azagayas y puntas largas: Son preferentemente de seccion circular y ovalada en el Magdaleniense superior, pero en la fase siguiente aparecen en similar proporción, 9, que

[15] Este dato es algo contradictorio con el hecho de que los núcleos de hojitas se hagan a partir de pequeños cantos sin descortezar totalmente (Lloret 1997: 144), cabe, sin embargo, la posibilidad de que no todos procedan de una primera obtención de láminas.

[16] Ver Apéndice 2. 
las de sección angulosa, 10, sobre todo rectangular. Entre las bases destacan las recortadas y en doble bisel en las ocupaciones inferiores y claramente las de doble bisel en el Magdaleniense final. Son piezas a menudo robustas aunque hay una gran variación de tamanos entre los que no faltan pequeñas puntas de base recortada. Semejantes a ellas, las puntas largas aparecen escasamente representadas por uno y dos ejemplares respectivamente. Se observa en las azagayas trazos diversos y surcos que bien pueden tener un objetivo funcional, bien plantearse como esquemas decorativos. Entre los elementos que pudieran tener un carácter funcional dos son los tipos mas extendidos. 1) acanaladura o ranura a veces muy ancha que recorre uno solo de los taterales del arma -6 piezas-, generalmente el derecho, apareciendo en prácticamente todos los niveles de la secuencia magdaleniense; en 3 casos mas se sitúan sobre ambos costados de las piezas (niveles IV-2 y IV-3). Una de las azagayas con ranura en el lateral izquierdo ofrece también tres estrias profundas y cortas, a modo de entalladuras, junto al ápice. 2) entalladuras o gruesos surcos perpendiculares al eje que pueden disponerse uni o bilateralmente, con dos ejemplos en el primer caso; también aparecen en toda la secuencia excepto III- 4 b y IV-4 y se documentan además sobre un lateral del bisel de una varilla del nivel $\mathrm{N}-2$. Como motivos propiamente decorativos hay un tema recurrente en los niveles IV- 4 a IV-2 y que aparece sobre tres azagayas y dos varillas. Es un motivo aflechado (Lám. III. 3 y 4) y está formado por un grueso trazo longitudinal cortado en su recorrido por uno, dos o tres trazos mas cortos dispuestos oblicuamente al anterior o convergiendo en su eje. Otros motivos son series de lineas paralelas entre sí situadas perpendicular o longitudinalmente al recorrido de la pieza, incisiones y/o estrias que recorren en sentido oblicuo la cara dorsal, un motivo en zigzag, asociados o no a los aflechados (Lám. III: 1, 2 y 3). Sobre un doble bisel roto aparecen trazos ajedrezados en el lateral derecho y un motivo semejante a la extremidad y cola de un pez en el izquierdo.

Varillas. Hay cinco ejemplares en toda la secuencia de los cuales solo dos poseen cierta entidad aunque les faltan ambos extremos. Son piezas de sección planoconvexa o subrectangular de aspecto menos cuidado que las azagayas. Dos, ya citadas, comparten motivos decorativos con estas, pero una de ellas, además de los temas aflechados sobre ambos costados, posee una decoración de tipo curvilíneo a base de óvalos enlazados por trazos longitudinales (Iám. III: 4). Sobre una tercera se observan estrúas finas e irregulares en el inicio del bisel, semejantes a las llamadas estrías de sujeción de estas zonas.

Arpones. Aparecen 4 en la fase superior y 13 en la final, siendo estos últimos muy variados en morfología. Durante la primera etapa, como es comín durante el Magdaleniense, solo se documentan arpones cilindricos de 1 hilera de dientes; entre ellos de las dos bases reconocibles una es de tipo cantábrico con pefforación ovalada lateral junto a una ancha protuberancia y la otra posee un abultamiento. Los arpones crecen en número y diversidad en la fase siguiente, sobre todo en el nivel $\mathrm{FV}-2$, el que más piezas proporciona. Predominan los arpones cilíndricos de 1 hilera de dientes, 9, frente a los de doble hilera, 1. En estos tipos las bases ofrecen el tipo cantábrico en cuatro casos, tres mas posee un abultamiento, hay dos con doble abultamiento y una base lisa. Pero quizá las piezas que más destacan en el conjunto del Magdaleniense final son dos arpones de sección aplanada, uno de ellos de doble hilera y del que se conserva solo el extremo distal con un diente a cada lado, es una pieza que debio de tener una gran envergadura ya que el frag- 
mento conservado, extremo distal y última fila de dientes, mide $3 \mathrm{~cm}$ de longitud (Lám. I: 4). El segundo es un magnífico ejemplar, completo, que posee una hilera con dos dientes y base con perforación circular en la zona central frente a una amplia protuberancia (Lám. I: 5). Los trazos grabados que aparecen en los arpones son muy diferentes a los de azagayas y varillas. Son comunes los helicoidales en torno a la base, relacionados con el sistema de enmangue y por tanto de carácter funcional. Como trazos propiamente decorativos aparecen series de pequeñas estrías oblicuas en los espacios interdentales en 12 de los ejemplares. Más escasos son otros motivos como series de pequeñas estrías en distintas direcciones bien en el lateral opuesto a los dientes o sobre la cara dorsal. Destacan dos arpones unilaterales con protuberancia simple decorados a lo largo de su fuste con temas figurativos ${ }^{[17]}$. Se trata de serpentiformes en distinto grado de esquematización; sobre uno de ellos del nivel III- $4 \mathrm{~b}$, el motivo aparece en dos ocasiones, en uno grabado destacando la cabeza y el cuerpo rallado a modo de anillos, junto a él otro esquematizado en grabado muy profundo, casi bajorrelieve (Lám. II: 1). En el segundo arpón, nivel IV-3, una serpiente con cabeza pentagonal destacada y cuerpo sin acabar pero cubierto de trazos interiores recorre el tercio distal de la pieza, situados debajo de esta figura aparecen dos husos abiertos rellenos de trazos interiores perpendiculares y oblicuos, enmarcando estos motivos hay dos series laterales de pequeñas estrías a lo largo de la pieza. Un tercer motivo, más dudoso, pudiera representar un pisciforme sobre el único arpón cilíndrico de dos hileras de dientes del nivel IV-2, el tema aparece muy borrado.

Punzones. Están entre los instrumentos mejor representados, sobre todo en el nivel IV-2, pero incluso aquí por debajo de las armas. Se trata por lo común de simples esquirlas con un extremo aguzado intencionalmente y sólo se computan dos piezas que conserven la base articular.

Agujas y núcleos de agujas. Aunque muy similares en número entre ambos conjuntos -5 y 6 respectivamente-, doblan su importancia porcentual en los niveles del Magdaleniense superior. Se trata de piezas de tamaño mas bien pequeño de las que muy pocas se conservan enteras. Algunas muestran evidencias de reelaboración. Junto a ellas se hallaron en los niveles IV-4 y IV-3 tres fragmentos oseos con huellas de ranurado y algunas lengüetas sin extraer, interpretados como núcleos de agujas ${ }^{[18]}$.

Colgantes. Los elementos de adorno personal de la Pila son muy monótonos y consisten en caninos atrofiados de cérvido que presentan una perforación en la zona de la raíz. Son relativamente numerosos en el nivel IV-2 donde se recogieron 11 ejemplares.

Espätulas: Se han recuperado 3, de ellas una es curvada, su forma recuerda a un pez, aparece decorada con dos series centrales de trazos oblicuos en el centro de la cara dorsal -que pudieran aludir a la espina central- y trazos radiales irregulares en el extremo distal.

Destaca también una extraña pieza en asta, acabada en bisel y con una gran perforación por donde se ha roto, para González.Sainz (1989) se trataría de una posible azuela.

[17] Gutiérrez Sáez, C.; Heras Martín, C.; Bernaldo de Quirós, F. (1986-87). Gutiérrez Sáez, C.; Bernaldo de Quirós, F. (1989).

[18] Gutiétrez Săez 2000. 
Hay, finalmente, en estos niveles 18 piezas diversa de candil de cérvido y de hueso que presentan distintas modificaciones como retoques, perforación o incisiones pero que no llegan a constituir instrumentos definidos. Destaca en el nivel IV-3 un fragmento de coxal que tiene grabado sobre su cara superior una figura completa de caballo'19\%. El animal ha sido delimitado por una línea doble en toda su silueta, tiene dos patas por par, trazos de pelaje en la cola y junto a los cuartos delanteros; en la zona superior se ha indicado la línea de crinera en escalón y de su boca sale un doble trazo, carece de otros detalles anatómicos internos. La figura guarda unas proporciones correctas pero ofrece cierta tosquedad en su esbozo.

\section{LAS OCUPACIONES AZIUIENSES}

\section{Estratigrafia, cronologia y entorno medioamblental}

Previamente a los niveles azilienses una capa de arcilla muy plástica se superpone a la última ocupación magdaleniense (IV-1) erosionando su parte superior. Esta capa, denominada III-4b, era prácticamente estéril aunque englobaba en su base un pequeño conjunto de materiales entre los que destacan dos arpones cilindricos de una hilera de dientes, de estilo claramente magdaleniense. Este hecho y la ausencia de materiales en la zona superior del nivel parecen indicar que este lote procedería del nivel IV-1

La secuencia azielense se desarrolla de la siguiente manera.

III-1. Nivel de tierra negra con conchero. Última ocupación Azielense.

III-2. Nivel más delgado de color marrón y consistencia arcillosa, con conchero. Aziliense

III-3. Semejante a III-1 en grosor y tonalidad, también con conchero. Aziliense. $11.700+70 \mathrm{BP}$

III-4. Capa de arcilla marron con menor potencia de conchero. Aziliense.

III-4b. Arcilla muy plástica, prácticamente estéril.

El conjunto de niveles azilienses, delimitados por la diferente textura y tonalidad de los sedimentos se caracteriza no obstante por la presencia de un conchero donde dominaban diferentes tipos de Patella junto con Littorina littorea. Esta masa de conchas era tan abundante en algunos sectores que prácticamente no había matriz sedimentaria, pero se enrarecían en la base de la secuencia, en los niveles III 4 y III- 4 b.

La única datación de este conjunto procede del nivel III-3 y da una fecha de $11.700+$ 70 BP (Gif 8148). Es una datación un poco temprana para un nivel aziliense, teniendo en cuenta además que no es el más antiguo de la secuencia, pero no desentona dentro del conjunto de fechas del Aziliense antiguo cantábrico ${ }^{(20)}$. Si una lectura estricta de su datación

[19] Gutiérez Sáez, C.; Heras Martin, C.; Bernaldo de Quirós, F. (1986-87).

[20] Fernández-Tresguerres Velasco 1995: $204 \mathrm{y}$ ss. 


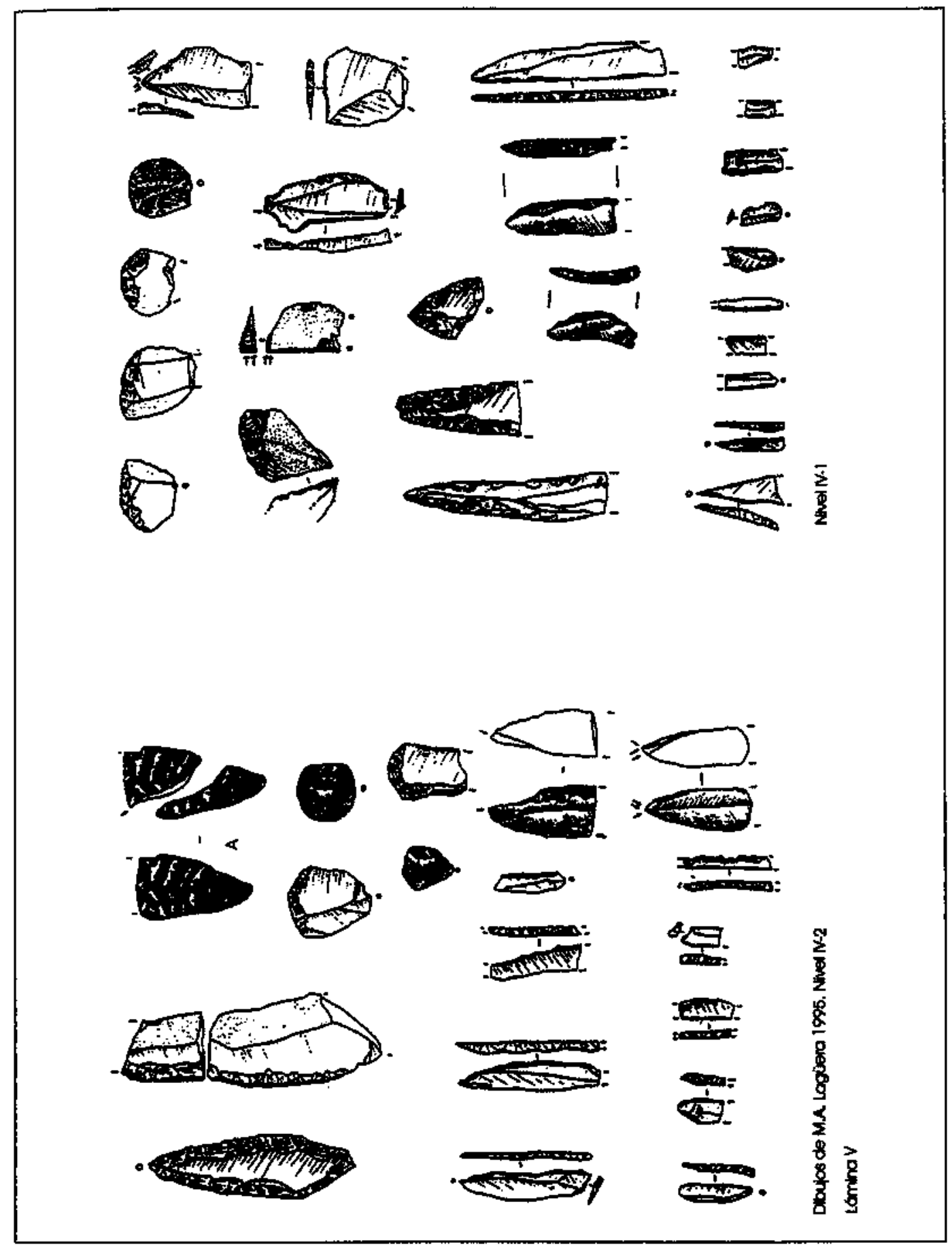

Lantua $V$ 


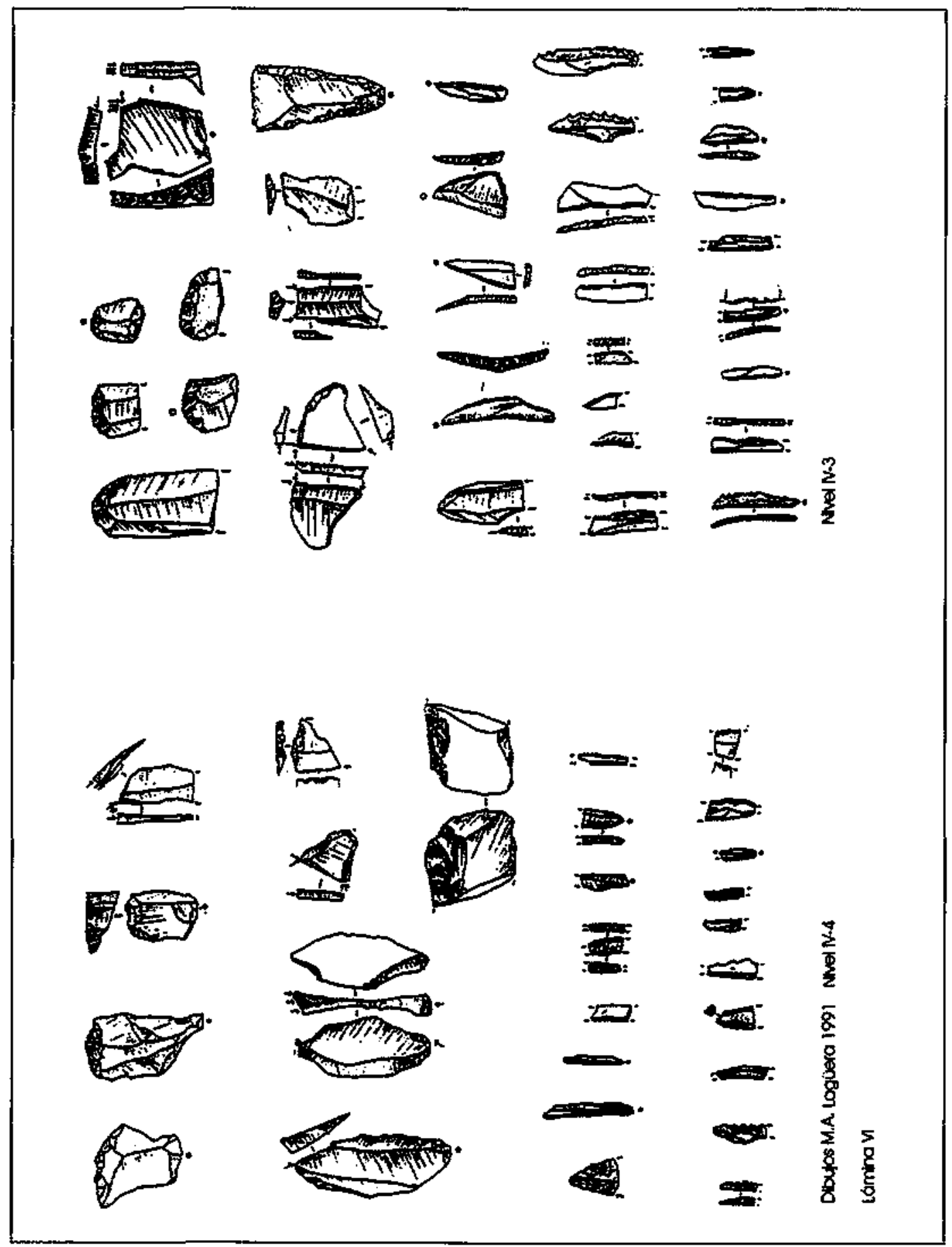

Lantina VT 
lo ubica en el tránsito de las fases Cantábrico VII a VII (11 700-10.800 BP), de ambiente mâs húnedo y atemperado, que se corresponde con la fase polínica Alleröd ${ }^{[2]}$, sus relaciones con otros conjuntos similares lo incluyen de pleno en esta úlitima fase. Redundando en este aspecto los análisis antracológicos revelan un atemperamiento climático frente al conjunto magdaleniense, con predominio de Betula junto con Populus y Rosaceas, dándose las mejores condiciones en la cima de la secuencia ya en el nivel III-1.

\section{La industria lítica ${ }^{(22,23]}$,}

El componente numérico de los cuatro niveles azilienses presenta cierto equilibrio dentro de su desigualdad. Los dos niveles de carácter arcilloso y espesor débil son escasos en efectivos, computándose 63 útiles en el III-4, nivel que inaugura las ocupaciones azilienses, y 58 en el III-2. A su vez los niveles III-3 y III-1, ambos de potente matriz terrosa y color negro intenso tienen respectivamente 331 y 301 piezas retocadas y no solo la muestra es mayor sino que la variedad tipológica se duplica respecto a los niveles anteriores. Esta disparidad introduce un sesgo a la distribución estadística, toda vez que las poblaciones de los niveles III -4 y III- 2 son demasiado exiguas, pero al menos estando intercalados no interrumpen del todo una visión de la secuencia.

Utillaje microlaminar. Domina el conjunto del instrumental en todos los niveles oscilando en aquellos de mayor número de útiles entre el $46.5 \%$ y $50.1 \%$, porcentaje que sube respectivamente hasta el 54 y $57.4 \%$ añadiendo la proporción de puntas azilienses; en total, de los instrumentos retocados en la secuencia aziliense de la Pila, poco mas de la mitad son pequeñas laminillas trabajadas con retoque abrupto. Entre esta variedad la mayoría se computa en la categoría de hojitas de dorso que aunque alcanzan un índice restringido superior al $70 \%$ en todos los niveles, decrecen porcentualmente desde el III -4 al III- 1 . El conjunto de hojitas no presenta demasiada variedad formal, pero se detecta un cierto interés por la producción de hojitas truncadas, sobre todo con dorso añadido que se incrementan de base a techo del $4.7 \%$ al $10.8 \%$. Las puntas azilienses, por su parte, tienen sus más altos porcentajes -en torno al 7\%- en los niveles III-3 y III-1

Raspadores. Ofrecen una frecuencia moderadamente alta decreciendo entre el 22.2 al $16.6 \%$ desde el Aziliense más antiguo al mas reciente. Entre los tipos son mayoría los simples y los fabricados sobre lámina, además, dentro de los tipos minoritarios están bien representados los circulares y los unguiformes.

Buriles. Están ausentes en el nivel III-2 y en el resto van disminuyendo paulatinamente según avanza esta fase. Predominan los diedros en los niveles más antiguos pero los de truncadura van cobrando importancia a techo de la secuencia, si bien el tipo más común es el de ángulo sobre rotura.

[21] Hoyos 1995.

[22] A partir de Lagüera García 1991.

[23] Lámina VI. 
Piezas con dorso y truncadas. Si exceptuamos las puntas azilienses comentadas ya, el peso de este grupo diverso recae en las truncaduras que disminuyen del $4.9 \%$ en el III3 al 2.4 en el II-1. Los dorsos tienen una escasa incidencia y como elemento curioso se incluyen dos microgravettes en el nivel III-2, el único de esta secuencia que presenta una frecuencia muy baja de puntas azilienses.

Piezas de retoque continuo. Su porcentaje es inferior al $7 \%$ siendo mayoria las que tienen el retoque sobre un solo lateral. De forma algo anecdótica se atestiguan dos láminas aurinacienses, una en cada nivel superior.

Sustrato. Los integrantes de este grupo crecen ligeramente del 7.9 al $11.2 \%$ desde las ocupaciones azilienses más antiguas a tenor sobre todo de las piezas astilladas, siguiendo en importancia las escotaduras y los denticulados.

Perforadores y Utiles compruestos. Son prácticamente inexistentes, se computan únicamente 6 perforadores y 2 piezas múltiples, que aparecen en los niveles III-3 y III-1, mas densamente poblados.

\section{Las industrias óseas}

A lo largo de las ocupaciones azilienses las industrias realizadas en hueso y asta son relativamente exiguas ya que solo se computan 24 piezas. De todo el conjunto destacan por su abundancia los arpones (20.8\%), y azagayas $(16.6 \%)$, junto a punzones y diversos fragmentos indeterminados.

Arpones. Son muy pocas las piezas completas aunque todo el conjunto se ajusta a los patrones azilienses de arpón con sección aplanada (Lám. I: 1, 2 y 3). Los 2 ejemplares enteros nos remiten a arpones de pequeño tamaño con una hilera de dos y tres dientes y perforación en ojal en la zona central de la base a la altura del arranque de los dientes. Un fragmento mesial muestra doble hilera de dientes, dos en cada lateral. En los tres casos los dientes son rectos y poco despegados del fuste. No se observa entre ellos ningún motivo decorativo o trazos de enmangue.

Azagayas. Hay cuatro piezas, ninguna completa. Dos fragmentos distales son apuntados, uno de sección rectangular y el otro circular; la tercera pieza es una base redondeada y el fragmento más completo muestra la zona meso-distal, de sección mas o menos circular; esta pieza tiene una serie de trazos cortos que rodean el fuste en su zona inferior y recuerdan a las marcas helicoidales que se observan sobre la base de muchos arpones, probablemente deban relacionarse con el sistema de enmangue.

Punzones. Se trata en este caso de tres esquirlas oseas con un extremo apuntado a las que habría que añadir una pieza similar pero algo mas elaborada, una punta de base abultada que conserva la base articular del hueso y pertenece al nivel III-1

Fragmentos varios. Son relativamente abundantes. Conforman 8 elementos diversos, entre ellos la parte intermedia de un candil de cérvido y dos fragmentos de hueso recorta* 
dos, en los otros aparecen distintas huellas a modo de las llamadas marcas de caza sobre tres piezas, además hay dos huesos con perforaciones -una de ellas natural- rodeadas de pequeños trazos radiales. En los niveles superiores revueltos se encontró un pequeño fragmento quemado con un motivo decorativo a base de series de pequeñas incisiones perpendiculares a un trazo mas largo, tema propio del Magdaleniense final y Aziliense ${ }^{[24]}$.

\section{EVOLUCIÓN DE LAS OCUPACIONES DE LA PIIA}

\section{El entorno paleoclimático}

A partir de la datación del nivel $\mathrm{N}-2,12.200+70 \mathrm{BP}$, se puede ubicar cronológicamente este estrato en la fase Cantábrico VII o Dryas II -12.700 a 11.700 , de clima frío y seco, sí bien aún con cierta humedad al principio de la secuencia. El inicio del Magdaleniense, niveles IV-4 y IV-3, en la cueva de la Pila quedaría situado bien a comienzos de esta misma fase o a finales de la anterior-Cantábrico VI o Bölling según polen, con una cronología ente 12700 a $13300 \mathrm{BP}$ - de clima muy húmedo y fresco con temperatura más suave que la propiamente glaciar pero sin llegar a la actual. Sin embargo no hay aún análisis sedimentológico ni de C14 que confirmen este hecho, solo a partir de paralelos con otros niveles de la Cornisa Cantábrica con industrias de un Magdaleniense superior inicial cabría incluir a estos niveles de base en los momentos más antiguos de la fase VII.

La parte superior de la secuencia, esto es, los niveles azilienses se desarrollan a caballo entre el Dryas II y el inicio del Alleröd a tenor de la datación del nivel III-3 cuya fecha, $11.700+70 \mathrm{BP}$, establece el límite entre ambas fases. La secuencia de ocupación de la cueva es, entonces, relativamente corta, probablemente no mayor de 1500 años o menos, desarrollada a partir de ocho estratos fértiles; otra cuestión es delimitar temporalmente las distintas ocupaciones ya que al menos en el nivel IV-2, dada su potencia y el hecho de ser un nivel de arroyada probablemente ofrezca los restos de mas de una ocupación.

La Pila se situaba en un entorno costero abrigado, de topografía con suaves altibajos y una cierta variedad de condiciones ecológicas lo que pudo dar lugar a un abanico relativamente amplio de posibilidades de captación de recursos. Los datos antracológicos inducen a pensar en una tendencia al atemperamiento climático de base a techo de la secuencia, donde no faltaron nunca masas boscosas incluso en los momentos generales más fríos.

\section{Evolución de la tecnologia}

Entiendo la tecnología en sentido amplio como el conjunto de conocimientos, procedimientos e instrumentos que permiten a un grupo humano intervenir sobre su medio

[24] González Sainz 1982, 1989: 255-6. 
ambiente. En este trabajo, en espera de datos más definitivos, la evolución tecnológica se ve limitada a la visión del conjunto instrumental más estereotipado, los útiles retocados en

piedra y el conjunto óseo. En el tránsito del Magdaleniense superior (niveles IV-4 y TV-3) al final (niveles IV-2, IV-1 y III-4b) y de este al Aziliense (niveles III-4 a III-1) los cambios que experimentan las industrias se reflejan a continuación.

\section{Industria lítica}

En una visión de conjunto del instrumental lítico retocado se observa que desde la base al techo de la secuencia se producen una serie de transformaciones muy graduales en el equipamiento industrial; la visión secuencial de estos cambios desde el Magdaleniense superior al Aziliense parece convertir al Magdaleniense final una clara etapa de transición. Estas tendencias suponen una redistribución de la importancia no solo de los distintos grupos de utillaje sino también de algunos tipos específicos de útiles, si bien esta última apreciación aparece muy matizada porcentualmente por el gran peso del utillaje microlaminar en todos los niveles.

Los pequeños elementos sobre laminilla suponen de forma generalizada en torno a la mitad del componente industrial de la secuencia, solo los niveles con efectivos líticos más reducidos se escapan a este comportamiento, dando indices más extremos en el III-4 y el III-2, en el resto la homogeneidad en cuanto a su porcentaje es la tónica. La composición interna de este grupo también refleja una serie da cambios aunque matizados. Así durante el Magdaleniense las hojitas son mas bien aplanadas y con un único dorso pero ya en el Aziliense crecen en importancia las hojitas con doble dorso y su espesor aumenta. Un segundo aspecto de la morfología de estas piezas es su terminación apuntada; en este sentido la presencia mas destacada de hojitas apuntadas se da casi a inicios de la secuencia, nivel IV-3, y en las últimas ocupaciones azilienses. Otras variaciones se deben a la disminución de las hojitas denticuladas, con o sin dorso, relativamente importantes en la base del magdaleniense pero que van decreciendo y ya en el último nivel de esta etapa apenas tienen representatividad hasta que desaparecen mediado el Aziliense. Inversamente mientras las denticuladas se agotan, las hojitas truncadas van cobrando peso hasta alcanzar una frecuencia no desdenable en las últimas ocupaciones. De forma paralela a ellas, las puntas azilienses están ausentes al inicio y desde la ocupación magdaleniense postrera se incrementan en frecuencia, sí bien con valores un poco más bajos que las truncadas.

Dos de los grupos que ven reducir sus efectivos a lo largo del tiempo son los buriles y las piezas de retoque continuo. En el primer caso hay un doble fenomeno, los buriles son el cuarto grupo en importancia cuantitativa en el nivel de base, IV-4, del Magdaleniense superior y a partir de aqui, incluso dentro de esta misma etapa van perdiendo importancia en las sucesivas ocupaciones para acabar como un utillaje residual en el nivel aziliense mas reciente; paralelamente a este fenómeno regresivo, si atendemos a la variedad tipológica, su mayor desarrollo se encuentra no en el Magdaleniense reciente, donde más abunda, sino en el final, en que su indice se ha reducido prácticamente a la mitad desde la fase anterior. Entre los tipos no se detectan grandes variaciones, solo cabe 
destacar que predominan los diedros sobre los de truncadura, gracias a la repetición del buril de ángulo sobre rotura; por su parte los de truncadura sobresalen en los niveles IV-2 y III-1.

Las piezas de retoque continuo van reduciendo sus efectivos desde el Magdaleniense al Aziliense, hecho que habrá que relacionar con el comportamiento del índice laminar. Hay que destacar entre estos tipos la presencia de las denominadas hojas magdaleniense en los últimos niveles de este período, con una presencia más importante cualitativa que cuanticativamente.

Si en la secuencia de la Pila hay grupos como las piezas microlaminares que se mantienen mientras que buriles y piezas de retoque continuo descienden, también se observan comportamientos distintos en el resto del conjunto industrial. Así los raspadores y las piezas con dorso o truncadura van en aumento si nos atenemos a una lectura estricta del grupo, mientras que el sustrato ofrece pocas variaciones.

Los raspadores son quizá los mas favorecidos a lo largo de las ocupaciones ya que pasan de porcentajes muy bajos a ser el segundo grupo en importancia desde el Magdaleniense final, si bien su apogeo se da en los niveles de transición entre esta etapa y el Aziliense, descendiendo ligeramente en el techo de la secuencia. Las formas mas buscadas son también las menos complejas, es decir los simples y los ejecutados sobre lasca, pero hay otras variaciones menores como por ejemplo la mayor abundancia de los construidos sobre lámina retocada en el Magdaleniense y un escaso pero creciente aumento de los circulares y unguiformes desde la fase final de esta etapa y a lo largo del Aziliense.

Respecto a los dorsos y truncaduras su estimación depende en buena medida de sí se considera este grupo estrictamente por el modo de retoque o bien se atiende además al soporte. En el primer caso se detecta un pequeño incremento desde la base al final del Aziliense, pero desglosando su composición según soportes elegidos los resultados varían. Así por ejemplo los tipos construidos sobre lámina o lasca, es decir, dorsos totales o parciales y truncaduras, tienen una representación pequeña pero poco variable en todos los niveles. Por su parte aquellas piezas con retoque abrupto pero sobre soporte laminilla o pequeña lámina apuntada como gravettes, microgravettes y puntas azilienses, son las que realmente se incrementan desde el Magdaleniense y sobre todo en el Aziliense. Son estas piezas, que personalmente encuentro mas asociadas al utillaje microlaminar, las que provocan la falsa impresión de incremento general del grupo.

Finalmente el sustrato, impulsado sobre todo por las piezas astilladas y, en menor medida, por las escotaduras, presentan porcentajes semejantes en ambos extremos de la secuencia descendiendo casi a la mitad en el último nivel magdaleniense y el primero aziliense.

\section{Industria ósea}

En general se ve una fuerte reducción de los elementos óseos, tanto cuantitativa como de variedad de grupos y tipos, desde la fase Magdaleniense a la Aziliense. Los niveles azilienses son tremendamente pobres en efectivos lo que contrasta sobremanera con la 
riqueza anterior. Ahora bien, el punto álgido de la industria $\sigma$ sea corresponde a la fase final del Magdaleniense dándose su descenso radical ya en el Aziliense.

Otro aspecto que ofrece algunos cambios interesantes es el tema de las decoraciones o lo que es lo mismo del arte mueble. Estas afectan a los restos óseos de distinta manera a lo largo de la secuencia. Durante las fases magdalenienses, aproximadamente un tercio del conjunto óseo presenta motivos decorativos simples o complejos, siendo estos últimos más abundantes proporcionalmente en el nivel IV-3 donde encontramos entre otros el arpón con la serpiente y los husos rellenos además del caballo grabado. Llama la atención también como a lo largo de los niveles magdalenienses hay temas como los motivos aflechados que se repiten en los tres principales niveles magdalenienses IV-4, IV-3 y IV-2, así como los serpentiformes sobre arpones de los niveles IV-3 y III $-4 \mathrm{~b}^{(25)}$. Por otra parte hay un bajo aunque significativo porcentaje de piezas -principalmente azagayas y arpones- que presentan huellas derivadas de modificaciones tecnol6gicas como estrías helicoidales en la base de los arpones o ranuras longitudinales en las azagayas, trazos destinados a mejorar su uso o facilitar el enmangue, que afectan por igual a ambas etapas magdalenienses. Estos datos y el buen acabado de las piezas, principalmente de arpones y azagayas más grandes, traducen la inversión de tiempo y esfuerzo dedicados por los grupos magdalenienses a este instrumental. Frente a ello en la secuencia aziliense se detecta una preocupacion decorativa algo menor y muy escaso interés por modificar el instrumental, la única huella tecnologica corresponde a marcas helicoidales sobre el fuste de una azagaya; parece, en consecuencia un instrumental más expeditivo aunque no por ello menos eficaz, como se ha señalado ya anteriormenteszol. Pero con todo, el principal cambio radica en los objetos a que se destina la decoración. Durante el aziliense todas las piezas con restos de motivos grabados son fragmentos oseos informes y además se trata siempre de temas simples como series de marcas de caza o estrias radiales en torno a una perforación. En el Magdaleniense, sin embargo, los principales elementos decorados son las azagayas -37-, los arpones -15además de 3 varillas y dos espátulas, los fragmentos amorfos son minoritarios, únicamente 6; entre los temas encontramos motivos geométricos simples o complejos y motivos figurativos con distinto grado de realismo.

Azagayas: Se da un progresivo descenso desde la base al techo de la secuencia pasando de representar casi la mitad del instrumental óseo en los niveles más antiguos, a poco mas de la cuarta parte durante el Magdaleniense final y apenas un sexto durante todo el Aziliense. Durante la etapa más antigua destacan las pequenas puntas de base recortada, seguidas por las azagayas en doble bisel, este último tipo será el predominante a lo largo del Magdaleniense final, por encima de las piezas monobiseladas y recortadas. En los niveles azilienses lo escaso y fragmentado del material impide su caracterización, la única base encontrada es redondeada. Las puntas largas, por su parte, son minoritarias durante las fases magdalenienses y desaparecen durante el Aziliense.

[25] Es decir, probablemente del IV-1 erosionado por III-4b.

[26] Fernández-Tresguerres Velasco 1981, 1995. 
Arpones. Inversamente a las azagayas los arpones ven crecer su importancia desde la base del Magdaleniense superior, donde representan apenas un $8.3 \%$, al final $-12.8 \%-y$, sobre todo, durante el Aziliense, cuando llegan a ser el tipo ligeramente mayoritario $-20.8 \%$ - Este cambio porcentual a lo largo de la secuencia va acompañado, a su vez, de una modificación en el diseño de los arpones. En primer lugar la diversidad en cuanto a tipos de sujeción de la pieza, representados durante el Magdaleniense por las bases con perforación más o menos ovalada dispuesta lateralmente, una perforación circular central, uno o doble abultamiento e incluso una base lisa, se ven sustituidos por un único modelo de base con perforación central en ojal. Varían igualmente otros atributos como los tamaños, muy diversos en longitud y grosor, durante el Magdaleniense frente a piezas únicamente pequeñas después. La forma de los dientes junto con la separación del fuste indica que predominan los dientes curvos moderadamente separados del fuste en el Magdaleniense superior, en la fase siguiente van siendo sustituidos por las morfologías en gancho bien despegadas del cuerpo del arpón y ya en el Aziliense los dientes son rectos y con la punta alejada del fuste. Curiosamente los dos fragmentos del nivel IV-1 indican tendencias distintas, el distal posee una doble hilera de dientes rectos similares a los azilienses, un segundo fragmento mesial presenta solo el arranque de los dientes, mientras que un diente suelto es de forma curva. En conjunto la variedad de formas y tamaños de los arpones magdalenienses de la Pila parece ser sustituida por un modelo homogeneo, sin embargo este hecho puede estar influido por el escaso número de piezas azilienses, cinco arpones de los cuales solo dos están enteros, frente a la riqueza magdaleniense. En este sentido las variaciones de los modelos azilienses han sido puestas de manifiesto en yacimientos donde abundan estas piezas, como sucede en la cueva de los Azules ${ }^{271}$.

Uno de los aspectos más interesantes de esta transición lo representan los ejemplares planos de los niveles magdalenienses, en especial el completo del nivel IV-2 que conjuga las dimensiones y los dientes propios del Magdaleniense con la sección aplanada y la ubicación central de la perforación típica de las piezas azilienses. En la Cornisa Cantábrica se conocen muy pocas piezas semejantes, en Los Azules nivel 5 ${ }^{(23)}$, La Paloma nivel 2(20), ambos en niveles azilienses y otras ya con tendencias claramente azilienses como Otero' ${ }^{1300}$. En la Pila este ejemplar completo aparece en un paquete sedimentario datado en torno a 12.200 BP y situado estratigráficamente en la base de la secuencia del Magdaleniense final; la pieza aplanada incompleta, por otra parte, pertenece al techo de esta secuencia. Estos datos junto a la temprana fecha aziliense de la Pila y otros yacimientos cantábricos, en momentos iniciales del Alleröd ponen en revisión la idea tan extendida en la bibliografía sobre la difusión del modelo de arpón aziliense en el Cantábrico desde Francia. La aportación de la Pila ${ }^{\mid 31}$ amplía geográfica y cronológicamente los focos donde, en pleno Dryas II, se está experimentando con este diseño de arpón plano. Desde mi punto de vista, hoy día

[27] Fernández Tresguerres y Junceda Quintana 1994.

[28] Femández Tresguerres y Junceda Quintana 1994; 89-90 y fig 2-2.

[29] Hoyos et alti 1980: 137.

[30] González Sainz 1989: 248, fig 31-19.

[31] Y quizá de otros sitios cantábricos pero con excavaciones antiguas. 
no parece un tema prioritario de la investigación conocer la localización geográfica estricta de este cambiois2), dado que son ya varios los sitios en que se dan estos ejemplares de transición ya desde Dryas II y, en cualquier caso, su difusión es muy rápida al conjunto de yacimientos con la generalización del Aziliense durante el Alleröd.

\section{Los instrumentos}

Este conjunto está integrado por piezas diversas como espátulas, punzones, agujas y sus matrices de extracción, cinceles-cuña y un posible yunque. Su situación a lo largo de las ocupaciones de la Pila presenta una distribución desigual y significativa. Los punzones son los únicos presentes en casi todos los niveles y su frecuencia evoluciona a lo largo de la estratigrafia pasando de ser muy escasos inicialmente $-6.2 \%$ - a duplicar su porcentaje durante el Magdaleniense final -11.8\%-. En el Aziliense presentan una importancia similar aunque se distribuyen exclusivamente en los dos niveles III-1 y III-3; a ellos hay que sumarles una punta de base abultada también del nivel III-1, lo que daría una representación conjunta del 16.6\%, siendo la mayor de toda la secuencia. El resto de las piezas mencionadas se localizan únicamente en los estratos magdalenienses, destacando las agujas y sus núcleos de extracción en la fase más antigua. Las agujas descenderán a la mitad durante la etapa siguiente para desaparecer finalmente ya en el Aziliense, ofreciendo así una evolución inversa a los punzones. El resto de elementos como las tres espátulas, el cincel-cuña y el yunque son todos del Magdaleniense final, con excepción de la espátula estrangulada y decorada a modo de posible pez, que es del nivel IV-3.

\section{Los adornos}

Son de una gran monotonía y están constituidos casi exclusivamente por caninos atrofiados de cérvido a los que se he realizado una perforación en la raiz; tienen cierta importancia durante el Magdaleniense final, $11.8 \%$, descendiendo en el resto de las fases. En el Aziliense, al único diente perforado es una patella con dos perforaciones, ambos son los únicos adornos de esta fase.

Otro aspecto a tener en cuenta es la evolución de las cadenas operativas óseas, de las que queda poca constancia en las sucesivas ocupaciones del yacimiento. Pese a haberse hallado restos de fauna muy numerosos las evidencias del proceso de manufactura no abundan. Entre ellas son reseñables los tres núcleos de agujas en hueso del Magdaleniense superior, un fragmento de azagaya con trazos de cortes en la cara dorsal que pudiera estar en elaboración además de un fragmento de lengüeta en asta con huellas de desbaste, ambos del final, y una base de arpón con perforación aziliense no acabada. Por otra parte la relación de materias primas es muy favorable al hueso, procedente de la caza, pero por

[32] Ni agudizar el viejo debate, tan caro a alganos paleolitistas a lo largo del siglo XX, de escoger como úrica explicación de los cambios, entre los que el arpón plano es uno de los mejores ejemplos, entre la idea de "ex Cantábrico hux" frente a "ex Francia lux" 
el contrario no abunda la materia bruta de asta que se reduce a 9 candiles de ciervo, de los cuales uno aziliense presenta estrias profundas en torno a su eje y otro del Magdaleniense final tiene huellas de recorte en la zona proximal; la escasez de esta materia prima no deja de ser un hecho sorprendente ya que la mayor parte de las piezas se han realizado sobre asta. En este sentido cabe aventurar que los útiles en hueso como agujas pudieron ser trabajados allí mismo, pero del grueso del conjunto en que se trabajaron instrumentos y armas no queda la misma constancia

\section{Conclusión}

En un trabajo anterior ${ }^{[33]}$ el equipo que trabajamos en la cueva de la Pila definimos el proceso de cambio entre el Magdaleniense y el Aziliense como una evolución en mosaico, caracterizada por transformaciones complejas y progresivas donde era patente la continuidad entre ambos. Hoy, con un conocimiento un poco más apurado de los materiales es posible matizar estas afirmaciones.

Se han mantenido distintas posturas sobre como evolucionan las industrias en piedra y hueso entre el Magdaleniense superior-final y el Aziliense, en ellas se sinúa la transición en el Magdaleniense final mediante un cambio gradual|3al o bien se habla de un corte más brusco ya en el Aziliensel35s pero dentro de una tendencia hacia la simplificación técnica y el pragmatismo patente ya en el Magdaleniense final.

La secuencia de la Pila es, hoy por hoy, una de las mas completas del Cantábrico en la transición de ambas fases y las tendencias que se perciben en ella son significativas. Se da un cambio lento y gradual, sin grandes rupruras, en aspectos como la industria lítica, la cual entra en un proceso de azilianización durante el Magdaleniense final que culminará en el Aziliense. Este proceso, que contempla la liquidación de los tiempos paleolíticos ha sido documentado $\mathrm{o}^{1361}$ en otros yacimientos con secuencias mas o menos completas entre ambas fases como en los Azules o el Piélago. De forma paralela, esta evolución gradual coexiste con un cambio más radical de orros fenómenos como armas e instrumentos óseos en lo industrial, el arte figurativo o los objetos decorados en lo conceptual y las formas de aprovechamiento del medio, patentes en la presencia de conchero únicamente en los niveles azilienses. En estos aspectos es perceptible la diferencia entre ambos bloques así como su homogeneidad interna, más matizable durante el Magdaleniense superior final que en el Aziliense ${ }^{[37]}$. Para C. González ${ }^{[38]}$ el descenso de las industrias óseas, tanto en volumen global como en diversidad formal y técnica, es propio de la fase final del período y se agudizará en el Aziliense, siguiendo un proceso semejante a la lítica, pero en la Pila no se obser-

[33] Bernaldo de Quiros et alii 1998.

[34] González Sainz 1989 y 1995.

[35] Fernández-Tresguerres Velasco 1981 y 1995.

[36] Fernández-Tresguerres Velasco 1981 y 1995.

[37] Principalmente en la Pila por la diferencia de muestra.

[38] González Sainz 1989: 228 y 269. 
va la disminución del instrumental óseo hasta los tiempos azilienses, dándose por el contrario en el Magdaleniense final una eclosión tanto en cantidad como en variedad de piezas. Por otra parte, la unidad dentro del Magdaleniense no es absoluta ya que la industria osea no es estrictamente la misma durante la etapa superior que en la final, y los tipos evolucionan en distinto sentido en ambas, teniendo esta evolución un claro entronque con el Aziliense. Las azagayas de la fase final no solo se reducen porcentualmente sino que conforman modelos en que el doble bisel es el tipo de inserción más común, y va quedando atrás la diversidad de bases que tuvo su mejor exponente durante el Magdaleniense medio y superior. Por el contrario, los arpones, que son los instrumentos en auge en la secuencia, desarrollan su máxima variedad técnica y morfológica en la etapa final, donde además empiezan a nacer los precedentes del arpón plano aziliense. Combinando ambos aspectos, si la variedad morfologica prima de forma distinta los dos tipos de instrumentos según etapas, la tecnologia, por el contrario tiende a hermanarlos ya que tanto los trazos con relación al enmangue u otros, la presencia de motivos decorativos y el cuidado acabado de las piezas son muy similares en las dos fases. Otro elemento de distinción entre Magdaleniense y Aziliense es la distribución de los elementos de trabajo más doméstico, con una fuerte reducción morfológica y quizá funcional del instrumental aziliense realizado en materias oseas frente a la riqueza cuantitativa pero, sobre todo, cualitativa del mundo magdaleniense. En la industria ósea y el arte mueble el cambio es, pues, brusco, pero dentro de él hay un factor de continuidad que es la lenta y gradual importancia de los arpones en detrimento de las azagayas. No cabe hablar de una sustitución de un arma por otra, dado que la fauna capturada con ellas es distinta, pero sí de una importancia cada vez mayor de los recursos fluviales y costeros a fines del Tardiglaciar.

No obstante, de una única secuencia, por muy pormenorizada que sea como la de la Pila, no pueden inferirse resultados a toda una región, factores como el tipo de ocupación con relación a una mayor o menor estacionalidad pueden encubrir o sobrevalorar diferentes aspectos. La dificultad para establecer la dinámica de los cambios en el tránsito del Magdaleniense superior-final al Aziliense en la Cornisa Cantábrica proviene de que no hay demasiados yacimientos que contengan una larga secuencia de esta sucesión y en otros, entre los que el Pendo, Castillo y Valle son algunos de los mejores ejemplos, la falta de divisiones estratigráficas finas dentro de lo que se tomó como único paquete sedimentario con una rica industria ósea imposibilita establecer con fiabilidad una evolución interna dentro del propio Magdaleniense. 


\section{BIBUIOGRAFIA}

ARMENDÁRIZ, A. (1990): Las cuevas sepulcrales en el País Vasco. Munibe 42, pp: 153-160

BERNALDO DE QUIROS, F.; GUTIÉRREZ SÁEZ, C.; HERAS MARTÍN, C.; LAGÜERA GARCIA, M.A.; PUMAREJO, P.; UZQULANO, P. (1992); Nouvelles donnes sur la transition Magdalénien supérieur - Azilien: La grotte de "La Pila" (Cantabria, Spagne). Coll. International de Periguex. Le peuplement Magdalenten, pp: 259-269.

FERNÁNDEZ-TRESGUERRES, J (1981): El Aziliense en las provincias de Asturias $y$ Santander Monografías del CIMA, 2.

FERNANDEZ-TRESGUERRES, J (1995): El Aziliense en la región cantábrica. Moure Romanillo, A; Gonzâlez Sainz, C. (Ed): El final del paleolítico cantábrico, pp: 199-224

FERNÁNDEZ TRESGUERRES, J.A.; JUNCEDA QUINTANA, F. (1994): Los arpones azilienses de la cueva de Los Azules (Cangas de Onís, Asturias). Homenaje al Dr. Joaquin Gonzälez Ecbegaray. Monografias CIMA 17, pp: 87-95

GONZÁlEZ SAINZ, C. (1982): Un colgante decorado de cueva Morín (Santander). Reflexiones sobre un tema decorativo de finales del Paleolítico Superior. Ars Praebistórica I, pp: 151-159

GONZÁLEZ SAINZ, C. (1989): El Magdaleniense superior-final de la región cantábrica. Tantín. Santander

GONZÁLEZ SAINZ, C. (1995): 13.000-11.000BP. El final de la época magdaleniense en la región cantábrica. Moure Romanillo, A.; González Sainz, C. (Ed): El final del paleolítico cantábrico, pp: $153-198$.

GUTIÉRREZ SÁEZ, C. (1999): Tecnología ósea. Agujas y sus matrices de extracción de la cueva de la Pila (Cuchía, Cantabria). Estudios en bomenaje al Profesor Dr García Guinea. Sautuola VI: 197-205.

GUTIÉRREZ SÁEZ, C.; HERAS MARTÍN, C.; BERNALDO DE QUIROSS, F. (1986-87): Arte mueble figurativo de la cueva de la Pila (Cuchía, Cantabria). Ars Praebistorica n 5-6, pp. 231-254. Madrid.

GUTIÉRREZ SÁEZ, C.; BERNALDO DE QUIROS, F. (1989): Dos arpones decorados de la cueva de la Pila, (Cuchía, Cantabria). Actas del XIX C.A.N., vol II, pp. 27-35. Zaragoza.

HOYOS GOMEZ, M. (1995): Cronoestratigrafía del Tardiglaciar en la región cantábrica. Moure Romanillo, A.; González Sainz, C. (Ed): El final del paleolítico cantábrico, pp: 15-76.

HOYOS GOMEZ, M.; MARTÍNEZ NAVARRETE, M.I., CHAPA BRUNET, T; CASTAÑOS, P; SANCHIIZ, F.B. (1980): La Cueva de la Paloma. Soto de las Regueras (Asturias). E.A.E. 116

LAGÜERA GARCfA, M.A. (1991): La tipología del utillaje lítico del yacimiento de La Pila (Cuchía, Mogro, Cantabria). Espacio, Tiempo y Forma, Serie I, IV, pP: 37-95

LLORET, M. (1997): El proceso tecnologico en el Magdaleniense superior de la cueva de la Pila (Cuchía, Cantabria). II Congreso de Arqueologia Peninsular, tomo I, pp: 141-146 
ANEXO I.

INDUSTRUA IITCA (LAGÜERA GARCIA 1991)

\begin{tabular}{|c|c|c|c|c|c|c|c|c|c|c|c|c|c|c|c|c|}
\hline TIFO No & III-I & 301 & HII-2 & 58 & HII-3 & 331 & III-4 & 63 & IV-1 & 32 & IV-2 & 930 & IV-3 & 164 & IV-4 & 173 \\
\hline 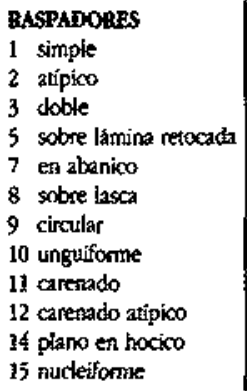 & $\begin{array}{l}50 \\
19 \\
3 \\
- \\
3 \\
5 \\
8 \\
4 \\
9 \\
1 \\
1\end{array}$ & $\begin{array}{l}2.6 \\
1.3 \\
2.9 \\
0.3 \\
0.3\end{array}$ & $\begin{array}{l}30 \\
3 \\
- \\
1 \\
- \\
- \\
4 \\
2 \\
- \\
- \\
- \\
- \\
-\end{array}$ & $\begin{array}{l}6.8 \\
3.4\end{array}$ & $\begin{array}{l}62 \\
24 \\
3 \\
- \\
2 \\
- \\
17 \\
7 \\
4 \\
1 \\
2 \\
- \\
2\end{array}$ & $\begin{array}{l}5.1 \\
2.1 \\
1.2 \\
0.3 \\
0.6\end{array}$ & $\begin{array}{l}14 \\
10 \\
- \\
- \\
- \\
- \\
3 \\
1 \\
- \\
- \\
- \\
- \\
-\end{array}$ & $\begin{array}{l}4.7 \\
1.5\end{array}$ & $\begin{array}{l}62 \\
30 \\
1 \\
3 \\
5 \\
- \\
17 \\
3 \\
1 \\
2 \\
- \\
- \\
-\end{array}$ & $\begin{array}{l}19.0 \\
9.2 \\
0.3 \\
0.9 \\
1.5\end{array}$ & $\begin{array}{l}158 \\
51 \\
6 \\
7 \\
12 \\
1 \\
53 \\
12 \\
3 \\
3 \\
4 \\
2 \\
4\end{array}$ & $\begin{array}{l}17.0 \\
5.4 \\
0.6 \\
0.7 \\
1.2 \\
0.1 \\
5.7 \\
1.2 \\
0.3 \\
0.3 \\
0.4 \\
0.2 \\
0.4\end{array}$ & $\begin{array}{l}14 \\
7 \\
1 \\
1 \\
2 \\
- \\
2 \\
- \\
- \\
- \\
- \\
\\
1\end{array}$ & $\begin{array}{l}8.5 \\
4.2 \\
0.6 \\
0.6 \\
1.2\end{array}$ & $\begin{array}{l}10 \\
3 \\
1 \\
1 \\
- \\
- \\
4 \\
- \\
- \\
- \\
\\
\\
\end{array}$ & $\begin{array}{l}5.7 \\
1.7 \\
0.5 \\
0.5\end{array}$ \\
\hline 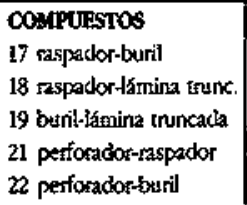 & $\begin{array}{l}- \\
- \\
- \\
- \\
-\end{array}$ & & $\begin{array}{l}- \\
- \\
- \\
- \\
-\end{array}$ & & $\begin{array}{l}2 \\
1 \\
1 \\
- \\
- \\
-\end{array}$ & $\begin{array}{l}0.6 \\
0.3 \\
0.3\end{array}$ & $\begin{array}{l}2 \\
- \\
1 \\
- \\
1 \\
-\end{array}$ & 1.5 & $\begin{array}{l}2 \\
\overline{-} \\
1 \\
- \\
1 \\
-\end{array}$ & 0.3 & $\begin{array}{l}14 \\
7 \\
5 \\
1 \\
- \\
1\end{array}$ & $\begin{array}{l}1.5 \\
0.7 \\
0.5 \\
0.1\end{array}$ & $\begin{array}{l}- \\
- \\
- \\
- \\
-\end{array}$ & & $\begin{array}{l}1 \\
- \\
1 \\
- \\
-\end{array}$ & 0.5 \\
\hline $\begin{array}{l}\text { PERFORADORES } \\
23 \text { petforador } \\
24 \text { bec } \\
25 \text { pefforador múltiple } \\
26 \text { micoppeforador }\end{array}$ & $\begin{array}{l}2 \\
- \\
2 \\
- \\
-\end{array}$ & 0.6 & $\begin{array}{l}\overline{-} \\
\overline{-} \\
- \\
-\end{array}$ & & $\begin{array}{l}4 \\
1 \\
1 \\
1 \\
1\end{array}$ & $\begin{array}{l}1.2 \\
0.3 \\
0.3 \\
0.3 \\
0.3\end{array}$ & $\begin{array}{l}1 \\
- \\
1 \\
- \\
-\end{array}$ & 1.5 & $\begin{array}{l}5 \\
2 \\
3 \\
- \\
- \\
\end{array}$ & $\begin{array}{l}1.5 \\
0.6 \\
0.9\end{array}$ & $\begin{array}{l}9 \\
2 \\
6 \\
1 \\
- \\
\end{array}$ & $\begin{array}{l}0.9 \\
0.2 \\
0.6 \\
0.1\end{array}$ & $\begin{array}{l}\overline{-} \\
- \\
- \\
- \\
-\end{array}$ & & $\begin{array}{l}1 \\
1 \\
- \\
- \\
-\end{array}$ & $\begin{array}{l}0.5 \\
0.5\end{array}$ \\
\hline 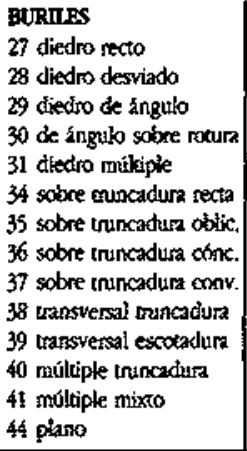 & $\begin{array}{l}13 \\
2 \\
5 \\
1 \\
4 \\
- \\
- \\
1 \\
2 \\
2 \\
1 \\
- \\
- \\
- \\
-\end{array}$ & $\begin{array}{l}0.3 \\
0.6 \\
0.6 \\
0.3\end{array}$ & $\begin{array}{l}- \\
\overline{-} \\
- \\
- \\
\bar{z} \\
\bar{z} \\
\bar{z} \\
\overline{-} \\
\overline{-} \\
\overline{-}\end{array}$ & & $\begin{array}{l}13 \\
2 \\
2 \\
2 \\
2 \\
1 \\
- \\
1 \\
3 \\
- \\
- \\
- \\
- \\
- \\
-\end{array}$ & $\begin{array}{l}3.9 \\
0.6 \\
0.6 \\
0.6 \\
0.6 \\
0.3\end{array}$ & $\begin{array}{l}4 \\
- \\
1 \\
- \\
3 \\
- \\
- \\
- \\
- \\
- \\
- \\
- \\
- \\
- \\
-\end{array}$ & 4.7 & $\begin{array}{l}15 \\
1 \\
1 \\
3 \\
5 \\
1 \\
1 \\
- \\
- \\
1 \\
1\end{array}$ & $\begin{array}{l}9.6 \\
0.3 \\
0.3 \\
0.9 \\
1.5 \\
0.3 \\
0.3\end{array}$ & $\begin{array}{c}55 \\
4 \\
7 \\
6 \\
9 \\
6 \\
1 \\
11 \\
5 \\
- \\
1 \\
- \\
3 \\
2 \\
-\end{array}$ & $\begin{array}{l}5.9 \\
0.4 \\
0.7 \\
0.6 \\
0.9 \\
0.6 \\
0.1 \\
1.1 \\
0.5\end{array}$ & $\begin{array}{l}10 \\
1 \\
1 \\
2 \\
2 \\
2 \\
- \\
- \\
- \\
- \\
- \\
1 \\
1 \\
- \\
-\end{array}$ & $\begin{array}{l}6.0 \\
0.6 \\
0.6 \\
1.2 \\
1.2 \\
1.2\end{array}$ & $\begin{array}{l}18 \\
- \\
2 \\
1 \\
6 \\
2 \\
- \\
1 \\
- \\
- \\
3 \\
1 \\
- \\
2 \\
-\end{array}$ & $\begin{array}{l}1.1 \\
0.5 \\
3.4 \\
1.1\end{array}$ \\
\hline 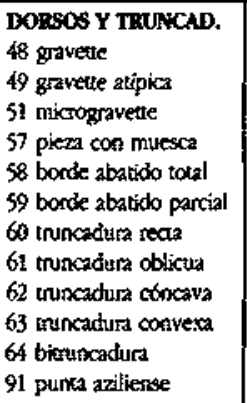 & $\begin{array}{l}35 \\
2 \\
- \\
- \\
1 \\
1 \\
1 \\
1 \\
3 \\
2 \\
1 \\
1 \\
22\end{array}$ & $\begin{array}{l}0.3 \\
0.3 \\
0.3 \\
0.3 \\
0.9 \\
0.6 \\
0.3 \\
0.3 \\
7.3\end{array}$ & $\begin{array}{l}4 \\
- \\
- \\
2 \\
- \\
- \\
- \\
1 \\
- \\
- \\
- \\
-\end{array}$ & 1.7 & $\begin{array}{l}48 \\
- \\
2 \\
1 \\
- \\
1 \\
3 \\
5 \\
5 \\
5 \\
1 \\
- \\
25\end{array}$ & $\begin{array}{l}0.3 \\
0.9 \\
1.5 \\
1.5 \\
1.5 \\
0.3\end{array}$ & $\begin{array}{l}6 \\
- \\
- \\
- \\
- \\
- \\
- \\
1 \\
- \\
2 \\
- \\
- \\
3\end{array}$ & 3.1 & $\begin{array}{l}35 \\
- \\
- \\
1 \\
- \\
1 \\
5 \\
2 \\
1 \\
6 \\
3 \\
- \\
21\end{array}$ & $\begin{array}{l}0.6 \\
0.3 \\
1.8 \\
0.9\end{array}$ & $\begin{array}{c}85 \\
- \\
- \\
4 \\
2 \\
2 \\
1 \\
10 \\
11 \\
18 \\
4 \\
3 \\
30\end{array}$ & $\begin{array}{l}0.4 \\
0.2 \\
0.2 \\
0.1 \\
1.0 \\
1.1 \\
1.9 \\
0.4 \\
0.3 \\
3.2\end{array}$ & $\begin{array}{l}30 \\
- \\
- \\
- \\
3 \\
- \\
- \\
1 \\
2 \\
3 \\
- \\
- \\
3\end{array}$ & $\begin{array}{l}0.6 \\
1.2 \\
1.8\end{array}$ & $\begin{array}{l}12 \\
- \\
- \\
- \\
2 \\
- \\
1 \\
2 \\
1 \\
1 \\
4 \\
1 \\
-\end{array}$ & $\begin{array}{l}0.5 \\
1.1 \\
0.5 \\
0.5 \\
2.3 \\
0.5\end{array}$ \\
\hline
\end{tabular}




\begin{tabular}{|c|c|c|c|c|c|c|c|c|c|c|c|c|c|c|c|c|}
\hline TUPO $\mathbf{N}^{\circ}$ & III-I & 301 & III-2 & 38 & III-3 & 331 & III-4 & 63 & IV-1 & 32 & N.2 & 930 & IV-3 & 164 & IV-4 & 173 \\
\hline PIRZAS RETOQUE & 21 & 6.9 & 1 & 1.7 & 15 & 5.3 & 4 & 6.3 & 23 & 7.0 & 68 & 7.3 & 20 & 12.1 & 20 & 11.5 \\
\hline CONT. & 13 & 4.3 & - & & 12 & 3.6 & 3 & 4.7 & 9 & 2.7 & 38 & 4.0 & 11 & 6.7 & 15 & 8.6 \\
\hline 65 sobre un borde & 7 & 2.3 & 1 & 1.7 & 3 & 0.9 & 1 & 1.5 & 7 & 2.1 & 19 & 2.0 & 9 & 5.4 & 4 & 2.3 \\
\hline 66 sobre dras bordes & 1 & 0.3 & - & & - & & - & & 7 & 2.1 & 11 & 1.1 & - & & 1 & 0.5 \\
\hline $\begin{array}{l}67 \text { timina auriaciense } \\
69 \text { punca de cara plana }\end{array}$ & - & & - & & - & & - & & - & & $\begin{array}{l}11+9 \\
0.1\end{array}$ & & - & & - & \\
\hline SUSTRATO & 34 & 11.2 & $B$ & 13.7 & 33 & 9.9 & 5 & 7.9 & 22 & 6.7 & 81 & 8.7 & 20 & 12.1 & 20 & 11.5 \\
\hline 74 escox & 6 & 1.9 & 3 & 5.1 & 4 & 1.2 & - & & 2 & 0.6 & 14 & 1.5 & 6 & 3.6 & & 3.4 \\
\hline 75 denticulataco & 3 & 0.9 & 1 & 1.7 & 6 & 1.8 & - & & 2 & 0.6 & 8 & 0.8 & 2 & 1.2 & 4 & 2.3 \\
\hline 76 pieza assillada & 22 & 7.3 & 3 & 5.1 & 21 & 6.3 & 5 & 7.9 & 17 & 5.2 & 51 & 5.4 & 11 & 6.7 & 9 & 5.2 \\
\hline$\pi$ raedera & 2 & 0.6 & 1 & 1.7 & 2 & 0.6 & - & & 1 & 0.3 & 6 & 0.6 & 1 & 0.6 & 1 & 0.5 \\
\hline 78 radere & 1 & 0.3 & - & & - & & - & & - & & 2 & 0.2 & - & & - & \\
\hline & $\begin{array}{c}151 \\
6\end{array}$ & 0.1 & 35 & 60.3 & $\begin{array}{c}154 \\
8\end{array}$ & $\begin{array}{c}46.5 \\
24\end{array}$ & 27 & 42.8 & $\begin{array}{c}161 \\
5\end{array}$ & 49.5 & $\begin{array}{c}45 \times 104 \\
7\end{array}$ & & 90 & 54.8 & 89 & 51.4 \\
\hline 85 de & 106 & 35.2 & 27 & 46. & 117 & 35 & 22 & 34. & 133 & & 353 & 37.9 & 73 & 44.5 & 63 & 36.4 \\
\hline 86 de d & 27 & 8.9 & 3 & 5.1 & 11 & 3.3 & 3 & 4. & 4 & 1.2 & 22 & 2.3 & 2 & 1.2 & 1 & 0.5 \\
\hline 87 ded & - & & - & & 1 & 0.3 & 1 & 1.5 & 2 & 0.6 & 32 & & 9 & 5.4 & 14 & 8.0 \\
\hline $88 \mathrm{der}$ & - & & - & & - & & - & & 2 & 0.6 & 4 & 0 . & 1 & 0.6 & - & \\
\hline 89 con escoxadura & 2 & 0.6 & l & 1.7 & - & & - & & - & & 3 & 0.3 & - & & 1 & 0.5 \\
\hline 90 dufour & 10 & 3.3 & 3 & 5.1 & 17 & 5.1 & 1 & 1.5 & 15 & 4.6 & 36 & 3. & 5 & 3.0 & 10 & 5.7 \\
\hline 92 varios & - & & - & & - & & $=$ & & - & & 2 & 0.2 & - & & - & \\
\hline
\end{tabular}

\section{ANEXO II. INDUSTRIA OSEA}

\begin{tabular}{|c|c|c|c|c|c|c|c|}
\hline Gupo & W & & ali 3 & als & and & & ONW \\
\hline ] & Azagayas & 4 & $16.6 \%$ & 29 & $28.7 \%$ & 21 & $43.75 \%$ \\
\hline IV & Pruntas largas & & - & 2 & $1.9 \%$ & 1 & $2.1 \%$ \\
\hline $\bar{v}$ & Puntas dee base aboultada & 1 & $4.1 \%$ & & - & & - \\
\hline VI] & Varillas & 1 & 4.196 & 3 & $2.9 \%$ & 2 & 4.196 \\
\hline XVI] & Arpones & 5 & $20.89 \%$ & 13 & $12.8 \%$ & 4 & $8.39 \%$ \\
\hline$\overline{X X X I}$ & Jłases de azagaya o arpón & & - & 2 & $1.9 \%$ & & - \\
\hline $\overrightarrow{v i}$ & Ésquirlas/punzones & 3 & $12.5 \%$ & 12 & $11.8 \%$ & 3 & $6.2 \%$ \\
\hline xाi & Cinceles cuña & & - & $\mathbf{1}$ & $0.9 \%$ & & - \\
\hline $\bar{x} \mathbf{x t}$ & Agufas & & - & 6 & $5.5 \%$ & 5 & $10.4 \%$ \\
\hline $\mathrm{XXX0}$ & Núcleas de agujus & & - & & & 3 & $6.2 \%$ \\
\hline $\mathrm{XXX1}$ & Yunques? & & - & 1 & $0.5 \%$ & & - \\
\hline$\overline{\mathrm{LX}}$ & Espátulas & & - & 2 & $1.9 \%$ & 1 & $2.1 \%$ \\
\hline xxy & Conchas colgante & 1 & $4.1 \%$ & & & & - \\
\hline XXV] & Dlenres colgantes & 1 & $4.1 \%$ & 12 & $11.8 \%$ & 3 & 6.29 \\
\hline$\overline{x x x}$ & Fragmemios con grabadios & 4 & $16.6 \%$ & 4 & $3 . \%$ & 1 & $2.1 \%$ \\
\hline$\overline{x \times X]}$ & Dientes de arjón & 1 & $4.1 \%$ & 2 & $1.5 \%$ & 1 & $2.1 \%$ \\
\hline$\overline{x \times x l}$ & Fragmentss indeteminados & 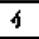 & $16.6 \%$ & 12 & 11.896 & 3 & 6.296 \\
\hline & TOTAE. & 24 & $100 \%$ & 101 & $100 \%$ & 48 & $100 \%$ \\
\hline
\end{tabular}

[39] Se exceptúa la punta de cara plana del cómputo de grupo.

[40] Se exceptúan las dos piezas de diversos del cómputo del grupo.

[41] Se añaden las 10 piezas de III-4́b porque es un nivel estéril que erostona la parte superior del IV sobre el que se superpone. Además las piezas aparecian en la base del nivel III-4b. 


\begin{tabular}{|c|c|c|c|c|c|c|c|c|c|c|c|c|}
\hline $\mathrm{GH}$ & 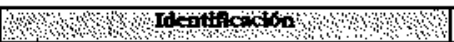 & Ppoz & mis & m2 & mis & ing & I & s? & ry & 2 & 28 & roct \\
\hline$\tilde{i}$ & Azazaya circular & $\cdot$ & & & 2 & & & & 5 & 4 & & 11 \\
\hline TI & Axagaya ovalada & 5 & & & & & & & 11 & 2 & & 3 \\
\hline$l$ & Arigaty' cuzdringalar & r & & & & & & & ? & & 2 & 3 \\
\hline I & Azagaya rectangular & $\cdot$ & 11 & & & & 1] & & 6 & & 1 & 9 \\
\hline $\mathbf{i}$ & Azagalya de base redoncieadia & 1 & & & & 1 & & & & & & 1 \\
\hline i & 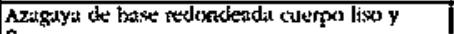 & $1+1$ & & & & & & & 1 & & in & 1 \\
\hline $\mathbf{i}$ & Azagaya de base nexomalial & 3 & & & & & & & 2 & 1 & 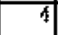 & 7 \\
\hline $\mathbf{i}$ & Aragaya de base monohiselacta & 4 & & & & & & & 7 & & & I. \\
\hline ! & Azagiyat de hase noonobiselud y sección & $\overline{4}$ & & & & & & & 1 & 11 & $?$ & 2 \\
\hline$\underline{1}$ & 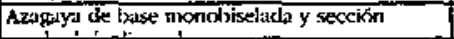 & $4-3$ & & & & & & & $!$ & & & 2 \\
\hline 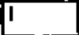 & Azagaya de buse en dofole biset & 5 & & & & & & & 7 & 2 & 2 & 12 \\
\hline 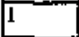 & Azagaya de baste en dextele bisel y sectikn & $5-1$ & & & & & & 1 & 2 & & & 3 \\
\hline 1 & 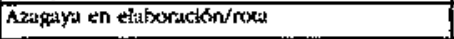 & - & & & & & & & ? & & & I \\
\hline IV & Puntas larga y serción cireutar & $\sqrt{3-1}$ & & & & & & & 0 & 1 & & 1 \\
\hline IV & Puntal zarga y seccikon cuadrangular & $13-3$ & & & & & & & 1 & & & 1 \\
\hline IV & Puncai larga y secxión rectargular & $13-3$ & & & & & & 1 & & & & 3 \\
\hline V & Punta de balse abujtada & 17 & 1) & & & & & & & & & $?$ \\
\hline $\mathrm{vi}$ & 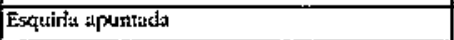 & 21 & 1 & & 2 & & 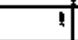 & 4 & 5 & 2 & 1 & 16 \\
\hline Vì & 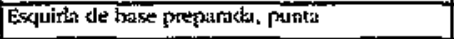 & $20-1$ & & & & & & & 2 & & & 2 \\
\hline VII & 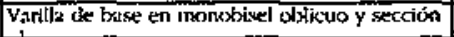 & $27-1$ & & & & & & & & & 1 & 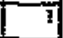 \\
\hline जाī & Varilla decoracta (rectillinea) & 30 & & & & & & & 1 & & & 1 \\
\hline VIil & 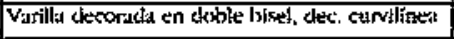 & $30-3$ & & & & & & & 11 & & & 1 \\
\hline Visi] & Vurilla tectargugut & - & & & & & 1) & & & 1 & & 2 \\
\hline IX & Esprátula che hase estristgulactia & $3 !-3$ & & & & & & & & 1 & & $!$ \\
\hline EX & Paletal lisa & $32-1$ & & & & & & & 2 & & & 2 \\
\hline $\mathrm{XII}$ & Cincet<uña & 37 & & & & & 1 & & & & & 1 \\
\hline xvit & Arțxan cilindrico de 1 hilema & $43 / 45$ & & & & & & 1 & !1 & & 2 & 4 \\
\hline Xnil & 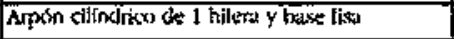 & $43-1$ & & & & & 1 & & & & & 1 \\
\hline Xviा & 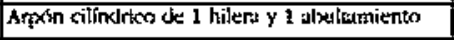 & $43-2$ & & & & & 1 & & 1 & 2 & & 3 \\
\hline$x \mathrm{xil}$ & Arpón ctindlike de 2 sthultamierstex & $43 / 44$ & & & & & & & 3 & & & 1 \\
\hline$x \sqrt{1}$ & ATxin cilindricn de 2 hileras y 1 alyultartiento & $44-2$ & & & & & & & $!$ & & & $\mathbf{i}$ \\
\hline $\mathrm{XVIT}$ & 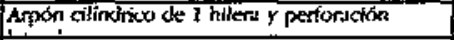 & $45-1$ & & & & & & & 4 & & 1 & 5 \\
\hline XVII & Arpón aplanacos de 2 hilenss & $46 / 48-2$ & & & 1 & & & 1 & & & & 2 \\
\hline Xvil & Arpón aplanack de 1 hilera y perfirsadón & $47-1$ & & & & & & & !! & & & 1 \\
\hline$x \mathrm{xit}$ & 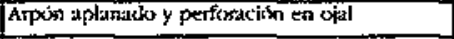 & 48 & 1 & & II & & & & & & & 2 \\
\hline$x$ in: & ATwion aplazado de ! hilera y perforackín en & $48-1$ & 1 & & 1 & & & & & & & $\overline{2}$ \\
\hline $\mathrm{XXI}$ & Aguian & 55 & & & & & & 1 & 3 & 1 & 2 & 7 \\
\hline$\overline{X x}$ & Aguja de cilbezal reckondeads o runculid & $55-2$ & & & & & & & 21 & & 2 & 4 \\
\hline$x \bar{x} \bar{i}$ & Contecta colpante con vatias perforaciones & $66-3$ & & & 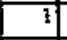 & & & & & & & $\overline{1}$ \\
\hline x'y & Diente colgante perforado fliso & $65-1$ & & 1 & & & & 1 & 11 & 3 & & 16 \\
\hline $\mathrm{XxX}$ & 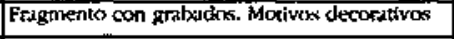 & $b 0-1$ & 2 & 2 & 1 & & & 2 & 2 & 1 & & 9 \\
\hline $\mathbf{x X X i}$ & Bulse de azagaya o arpón & 82 & & & & & & & 2 & & & 2 \\
\hline XXO'1 & Diente de aspon & 82 & & & 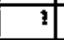 & & 2 & ] & & 1 & & 4 \\
\hline$\overline{x x D}$ & Fragmento apianato o alpuntads & 82 & & & & 1 & & 2 & 1 & & & 4 \\
\hline XXXI & Frigmento con traxisín & 82 & & & & & & & 1 & & & 1 \\
\hline $\mathrm{XXXI}$ & Fragnento con retorte $y / 0$ perforyackón & 82 & & 1 & 1 & & & & 1 & & & 3 \\
\hline $\bar{x} \times \mathbf{x}$ & Fragmento con rexpaptess & 82 & & & & & & 1 & & 1 & & 2 \\
\hline$x \times x \mid$ & Fragmente de carridi & 82 & 1 & & & & 11 & 3 & 4 & 3 & $\mathrm{~T}$ & 9 \\
\hline $\mathrm{XxXI}$ & Fragmento de lenguietal & 32 & & & & & 11 & & & & & 1 \\
\hline $\mathrm{xxxl}$ & Núcteo de agujas & 82 & & & & & & & & 2 & $?$ & 3 \\
\hline$\overline{X x \mathbf{x a}}$ & Yunque? & 83 & & & & & 3 & & & & & 1 \\
\hline
\end{tabular}

